\title{
Characterization of the Effects of Different Tempers and Aging Temperatures on the Precipitation Behavior of Al-Mg (5.25 at.\%)-Mn Alloys
}

\author{
Gaosong $\mathrm{Yi}^{1}$, Kenneth C. Littrell ${ }^{2}$, Jonathan D. Poplawsky ${ }^{3}$, David A. Cullen ${ }^{4}$, Erik Sundberg ${ }^{1}$, Michael L. Free ${ }^{1}$ \\ ${ }^{1}$ Department of Metallurgical Engineering, University of Utah, Salt Lake City, UT 84112, USA \\ ${ }^{2}$ Chemical and Engineering Materials Division, Oak Ridge National Laboratory, Oak Ridge, TN 37831 \\ ${ }^{3}$ Center for Nanophase Materials Sciences, Oak Ridge National Laboratory, Oak Ridge, TN 37831 \\ ${ }^{4}$ Materials Science \& Technology Division, Oak Ridge National Laboratory, Oak Ridge, TN 37831
}

\begin{abstract}
Corresponding author: Tel +1 8019196298, E-mail address: gaosong.yi@utah.edu
Department of Metallurgical Engineering, University of Utah, 135 S 1460 E, Rm412, Salt Lake City, UT 84112, USA
\end{abstract}

\begin{abstract}
The effects of different tempers (H131 and H116) and different aging temperatures (50 and $70{ }^{\circ} \mathrm{O}$ ) on the precipitation behavior of Al-Mg (5.25 at.\%)-Mn (Al 5083) alloys aged for a long time (41 and 30 months) were investigated using electron backscatter diffraction(EBSD), scanning transmission electron microscopy(STEM), energy-dispersive X-ray spectroscopy(EDS), atom probe tomography (APT), and small angle neutron scattering (SANS). GP zones and $\beta$ ” phases were found in Al $5083 \mathrm{H} 116$ aged at $50^{\circ} \mathrm{C}$ for 24 months using APT. EDS and SANS results revealed that a phase transformation process from GP zones to $\beta$ '/ $\beta$ phases occurred for precipitates formed in both $\mathrm{Al} 5083 \mathrm{H} 131$ and $\mathrm{H} 116$ aged at $70{ }^{\circ} \mathrm{C}$. The effective diffusion coefficient of $\mathrm{Mg}$ in $\mathrm{Al} 5083 \mathrm{H} 131$ is 1.8 times of that in $\mathrm{Al} 5083 \mathrm{H} 116$ aged at $7 \mathrm{CC}$. The precipitation process in $\mathrm{Al} 5083 \mathrm{H} 116$ aged at $50{ }^{\circ} \mathrm{C}$ is much slower than that in the sample aged at $70{ }^{\circ} \mathrm{C}$. The coarsening process was identified in $\mathrm{Al} 5083 \mathrm{H} 131$ and H116 aged at $70{ }^{\circ} \mathrm{C}$ for more than 9 months.
\end{abstract}

Keywords: Aluminum alloys, Precipitation, Atom-probe Tomography, Small Angle Neutron Scattering 


\section{Introduction}

Al-Mg 5xxx alloys are widely used in marine, transportation, structural components, and military applications for their high strength, low density, good weldability, and excellent corrosion resistance.[1] However, Mg is supersaturated in the matrix of $\mathrm{Al} 5 x x x$ alloys (for example, 4.0-4.9 wt.\% $\mathrm{Mg}$ in $\mathrm{Al} 5083$ ). The excess $\mathrm{Mg}$ will diffuse out and form intergranular $\beta$ phase when exposed to elevated temperature (50-200 ${ }^{\circ} \mathrm{C}$ ) for a relatively long time.[2-4] Intergranular corrosion occurs as a consequence of the selective dissolution of $\beta$ phase, which is anodic relative to the matrix.[5][6] Extensive research has been conducted on the mechanism of $\beta$ phase related corrosion in Al 5083.[7-9]

Various experimental techniques have been used to investigate the precipitation process in the Al-Mg binary system. Gault et al. [10] investigated the precipitation in polycrystalline and single crystalline Al-Mg alloys by means of ultrasonic analysis, and their results revealed that the formation of GP zones at low temperatures caused an increase of ultrasonic velocities, while the $\beta$ ' and $\beta$ phase formed at high temperatures decreases the ultrasonic velocities. A calorimetric study was conducted by Nozato and Ishihara[11] to examine the precipitation process in $\mathrm{Al}-\mathrm{Mg}$ (7.6-12.5 at.\%) alloys, and a four-stage precipitation process was proposed to explain the specific heat versus temperature results below $50{ }^{\circ} \mathrm{C}$ In addition, the formation of $\beta$ ' and $\beta$ phase was associated with the micro hardness change during the aging process. Recently, more details of the precipitation process in Al-Mg alloys, such as the lattice structure, limited formation temperatures, and shape of different precipitates, were obtained from the electrical resistivity measurement, calorimetry, small angle neutron scattering (SANS), and high resolution transmission electron microscopy (HRTEM) results. [12-20] From the results of these works, the precipitation sequence [21] in Al-Mg alloy is established as:

Supersaturated solid solution-GP zone- $\beta^{\prime \prime}-\beta$ ' $-\beta$ phase.

where GP (Guinier-Preston) zones (short-range ordered $\mathrm{Al}_{3} \mathrm{Mg}$ ) have a modulated structure[12] under the TEM, and $\beta$ ” phase (long-range ordered $\mathrm{Al}_{3} \mathrm{Mg}, \mathrm{a}=0.408 \mathrm{~nm}$ ) has an $\mathrm{L}_{2}$ structure in which $\mathrm{Al}$ and $\mathrm{Mg}$ atoms are alternatively aligned along the [100] directions [21]. $\beta$ ' phase, $\mathrm{Al}_{3} \mathrm{Mg}_{2}$, is reported to have a hexagonal 
(a=1.002nm, $c=1.636 \mathrm{~nm}$ ) structure and be semi-coherent with the matrix[14]. The equilibrium $\beta$ phase, $\mathrm{Al}_{3} \mathrm{Mg}_{2}$, is of fcc structure (a=2.824nm) with a unit cell containing 1186 atoms.[22] However, the precipitation sequence can be slightly changed if aging temperature or Mg content is different. Nozato and Ishihara[11] reported that GP zones and $\beta$ " phases will not form in the matrix if the aging temperature is higher than $90{ }^{\circ} \mathrm{C}$ Sato and Kamio [23] found that $\beta$ ” phase will form directly in the matrix of Al-Mg alloys with a Mg content higher than 20 at.\%, which is consistent with the results of Osamura and Ogura [21].

Atom probe tomography (APT) has been used to characterize nanoscale precipitates for several decades, and its use has expanded significantly with the invention of the local electrode atom probe (LEAP).[24,25] Aboulfadl et al.[26] investigated the cold rolled (90\% reduction in thickness direction) and stabilized Al-4.8 at.\% Mg alloy aged at $120^{\circ} \mathrm{C}$ for 20 hours, and a Mg-rich precipitate of $23 \mathrm{~nm}$ in length was found to form along <110> aligned dislocations. Mg concentration in the precipitate is 12 at.\% as obtained from APT. In addition, they also observed the asymmetrical distribution of $\mathrm{Mg}$ above and below the slip plane of dislocations. Homogenized $\mathrm{Al}-\mathrm{Mg}(5.8$ at.\%) alloys were processed by high-pressure torsion (HPT) at room temperature and $200{ }^{\circ} \mathrm{C}[27]$ TEM and APT results reveals that Mg-rich clusters (10-20 at.\% $\mathrm{Mg}$, and 5-10 nm) have formed near grain boundaries of the sample processed at room temperature. A significant fraction of the grain boundary is covered by a layer (10 nm in thickness) of Mg-rich precipitates in the $200{ }^{\circ} \mathrm{C}$ processed sample. Deformation induced vacancies were applied to explain the diffusion of Mg to the grain boundary.[27] SANS is a powerful technique to provide information such as size and number density of precipitates in a bulk sample of centimeter scale[28]. Roth and Raynal [16] aged two types of $\mathrm{Al}-\mathrm{Mg}(7 \%$ and $11.5 \% \mathrm{Mg}$ ) alloys at different temperatures (room temperature for 1 year and $40{ }^{\circ} \mathrm{C}$ for 3 months plus room temperature for 9 months). SANS results of these samples indicated that Mg-rich (20-25\%) zones are able to form in Al-11.5\% Mg alloys. Further research [17] by the same authors revealed that GP zones of $19 \AA$ in radius were identified in the $\mathrm{Al}-11.5 \% \mathrm{Mg}$ alloy aged at $0{ }^{\circ} \mathrm{C}$ for 9 months, and $\mathrm{Mg}$ concentration in the GP zone was estimated to be $19 \%$.

Even though extensive research has been conducted on the precipitation behavior of $\mathrm{Al} 5 \mathrm{xxx}$ alloys aged at relatively high temperatures, little information exists on the effects of different tempers and different low aging 
temperatures on the precipitation behavior of $\beta$ phase in Al 5xxx alloys. In this study, $\mathrm{Al} 5083$ alloys of different tempers, H131 and H116, were aged at relatively low temperatures (50 and $70{ }^{\circ} \mathrm{O}$ ) for a long time (30 months at $70{ }^{\circ} \mathrm{C}$ and 41 months at $50{ }^{\circ} \mathrm{C}$. The precipitates within the matrix were characterized using STEM, energydispersive X-ray spectroscopy (EDS), APT, and SANS. The effects of different tempers and aging temperatures on the precipitation behavior of Mg-rich precipitates were investigated.

\section{Experimental Procedure}

\subsection{Materials and treatment}

Commercial Al 5083 H131 and Al 5083 H116 alloys received from Alcoa Inc. were used in this research. For Al 5xxx alloys, H1xx is a strain hardened only temper, and the second digit of the temper represents the strain hardening extent.[29] For example, Hx8 is the fully hardened temper (approximately 75\% cold reduction after full annealing), and $\mathrm{Hx} 1$ and $\mathrm{Hx} 3$ stands for $1 / 8$ and 3/8 hard of the Hx8 temper respectively. The third digit "1" of H131 means the strain hardened degree is less than the controlled H13 temper, and H116 is a special corrosionresistant temper.[29] The as quenched (AQ) Al 5083 H131 and H116 samples were processed by homogenizing the samples at $450{ }^{\circ} \mathrm{C}$ for 3 hours and subsequently quenching in ice water. The AQ samples were examined using SANS to obtain the scattering intensities of the matrix for both alloys. The size of the sample used for the aging experiments was $1 \mathrm{~cm} \times 1 \mathrm{~cm} \times 1 \mathrm{~cm}$. As received Al $5083 \mathrm{H} 131$ alloy samples were put into an oven and aged at $70{ }^{\circ} \mathrm{C}$ for 1.5, 9, 18, and 30 months. As received Al $5083 \mathrm{H} 116$ alloy samples were aged at $70{ }^{\circ} \mathrm{C}$ for 3, 9, 18, and 30 months and at $50{ }^{\circ} \mathrm{C}$ for 9,24 , and 41 months. The temperature was selected based on measured deck sample temperatures of a navy ship traveling to different parts of the world.[30] The temperatures of the ovens were monitored using thermometers. The chemical composition of Al 5083 H131 and Al 5083 H116 are presented in Table 1. The micro hardness of Al $5083 \mathrm{H} 131$ is 107.1 $\pm 4.2 \mathrm{HRC}$, which is larger than that of Al $5083 \mathrm{H} 116$ (89.8 \pm 2.5 HRC).

\subsection{Characterization techniques}


For electron backscatter diffraction (EBSD), the samples were prepared using SiC polishing papers (P240 and P600), UltraPol polishing cloth with $9 \mu \mathrm{m}$ suspension of alumina, Trident polishing cloth with $3 \mu \mathrm{m}$ suspension alumina, and finished by ChemoMet with $50 \mathrm{~nm}$ colloidal silica suspension for 4 hours. The EBSD results were collected using an FEI Quanta 600 scanning electron microscope (SEM) equipped with a field emission gun electron source (FEG) and an EBSD detector. To obtain the geometrically necessary dislocation (GND) density, a scanning step size of $0.5 \mu \mathrm{m}$ was adopted. The acquired EBSD datasets were processed using the TSL-OIM Analysis $^{\mathrm{TM}}$ (Version 7) software (EDAX Inc., USA). In order to extract GND density results from the software, two parameters need to be set. First, the limit of the general grain boundary misorientation was defined as 4 , and any misorientation greater than this value was considered to be caused by grain boundary rather than GND. The local misorientation of every single point was then determined by the 24 surrounding points ( $2^{\text {nd }}$ nearest neighbor). More details of how to calculated GND can be found in Ref. [31], [32], and [33].

A Hitachi HF-3300 STEM/TEM (operate at $200 \mathrm{kV}$ ) equipped with a Bruker SDD-EDS detector, and a JEOL 2800 STEM/TEM (operate at $200 \mathrm{kV}$ ) equipped with an ultrafast EDS system (dual high counts SDD-EDS detectors) were used to characterize the microstructure of Al 5083 H131 and H116 alloy samples. TEM foils were prepared by mechanically polishing the samples ( $3 \mathrm{~mm}$ in diameter) to a thickness of $10 \mu \mathrm{m}$ using a Gatan dimple grinder, followed by ion milling using a Fischione $1010 \mathrm{Ar}$ ion mill. The ion mill was operated at $4 \mathrm{kV}$ with an incident angle of $9 \mathrm{deg}$, and final cleaning was performed at $3 \mathrm{kV}$ with an incident angle of $4 \mathrm{deg}$.

APT needle-shaped samples were prepared by top-down and cross-sectional FIB lift-out methods[34] using an FEI Nova 200 dual beam SEM/focused ion beam (FIB). The lift-out section was subsequently mounted on a microtip array post that was annularly milled (30 kV) and cleaned with a $5 \mathrm{kV}$ ion beam to make needle-shaped specimens suitable for field evaporation.[35] APT analyses were performed using CAMECA Instruments LEAP 4000 XHR. The LEAP was operated in laser-pulse mode with a specimen temperature of $30 \mathrm{~K}$, a pulse repetition rate of $200 \mathrm{kHz}$, a $100 \mathrm{pJ}$ laser energy, and a $0.5 \%$ to $1 \%$ detection rate. The resulting data were reconstructed and analyzed using commercial CAMECA IVAS software. 
Small angle neutron scattering (SANS) was performed at ORNL High Flux Isotope Reactor (HFIR) General Purpose Small Angle Neutron Scattering (GP-SANS) instrument.[36] The size of the SANS sample is $10 \times 10 \times 1$ $\mathrm{mm}$, both sides of the sample surface $(10 \times 10 \mathrm{~mm})$ were ground using SiC polishing paper, finishing with 1200 grit. The wavelength (obtained by a mechanical velocity selector) of the incident neutron beam was $\lambda=0.472 \mathrm{~nm}$ with a spread of $15 \%$. The data were measured at two settings-sample to detector distances of $7.829 \mathrm{~m}$ and 1.129 $\mathrm{m}$, using $0.472 \mathrm{~nm}$ neutrons in both. The data were collected using the $1 \mathrm{~m}$ square $8 \mathrm{~mm}$ diameter linear gas tube helium detector array, which was offset from the center in the $y$-axis $(0.665 \mathrm{~m})$ in order to measure a larger scattering vector $(q)$ range. The scattering vector magnitude equals to $(4 \pi \sin \varphi / \lambda)$, where $2 \varphi$ is the scattering angle. The overall range of $q$ is from $0.007 \AA^{-1}$ to $0.7 \AA^{-1}$. The data collection times were $1800 \mathrm{~s}$, and all SANS measurements were conducted at room temperature.

The SANS raw data was reduced to absolute scattering intensities $d \Sigma(q) / d \Omega$ after correction for transmission, background, and thickness using the package of routines developed at HFIR operating in the Wavemetrics Igor Pro software environment. Data obtained in the $q$ range of $0.05 \sim 0.7 \AA^{-1}$ was scaled to the match the data acquired from the $q$ range of $0.007 \sim 0.1 \AA^{-1}$ to generate the combined curves.

\section{Results}

\subsection{Microstructure}

Fig. 1(a) and (b) shows the inversed pole figure maps of as received Al $5083 \mathrm{H} 131$ and Al $5083 \mathrm{H} 116$, respectively. Most grains of Al 5083 H131 exhibited a lamellar structure which was elongated along the rolling direction (RD) (see Fig. 1(a)). The average width of the grain along the normal direction (ND) is about $16 \mu \mathrm{m}$, and the average aspect ratio of the grain is $\sim 25$. Furthermore, some subgrain boundaries (highlighted by dash arrows in Fig. 1(a) and (b)) have already formed in the elongated grain matrix of Al $5083 \mathrm{H} 131$ and H116, but more subgrain boundaries are observed in Al 5083 H131. As shown in Fig. 1(b), some coarse grains of Al 5083 H116 are also elongated along the RD, and the size of the largest grain is about $700 \mu \mathrm{m}$ in length and $200 \mu \mathrm{m}$ in 
width. In addition, some equiaxed grains are also observed in Al 5083 H116, as highlighted in Fig. 1(b). Most coarse grains in Al $5083 \mathrm{H} 116$ share the orientation of (101). Fig. 1(c) demonstrates the grain size (in diameter) distribution of Al $5083 \mathrm{H} 131$ and H116. The average diameter of Al $5083 \mathrm{H} 131$ is $9.1 \mu \mathrm{m}$, which is smaller than that $(17 \mu \mathrm{m})$ of $\mathrm{Al} 5083 \mathrm{H} 116$. The grain boundary misorientation angle results are presented in Fig. 1(d). The fraction of low angle grain boundary (LAGB, $2^{\circ}<\theta<15, \theta$ is the grain boundary misorientation angle) for Al 5083 $\mathrm{H} 131$ is 0.84 , which is slightly larger than that (0.77) of Al $5083 \mathrm{H} 116$.

Fig. 2 (a) and (b) shows the geometrically necessary dislocation (GND) density mapping results for (a) Al 5083 H131 and (b) H116. Compared with the grain matrix, the grain boundary regions (highlighted by arrows) have a relatively higher GND density in both alloys, which is consistent with previous study[37]. The average GND density for Al $5083 \mathrm{H} 131$ and $\mathrm{H} 116$ is $5.33 \times 10^{13} \mathrm{~m}^{-2}$ and $3.28 \times 10^{13} \mathrm{~m}^{-2}$, respectively.

The bright field STEM images of as received Al 5083 H131 and H116 are shown in Fig. 3 (a) and (c). In the matrix of H131 and H116, rod-like and plate-like pre-existing particles (indicated by “×”) are observed, which could be $\mathrm{Al}_{6}(\mathrm{Mn}, \mathrm{Cr}, \mathrm{Fe})$ type pre-existing particles as reported [19,38] previously. Dislocation networks (highlighted by arrows) are also found in the matrix of both alloys. Two high resolution TEM images of Al 5083 H131 and H116 are shown in Fig. 3 (b) and (d), and the inserted fast Fourier transform (FFT) patterns reveal no precipitates in the matrix.

Fig. 4 (a) is the bright field (BF) STEM image of Al $5083 \mathrm{H} 131$ aged at $70{ }^{\circ} \mathrm{C}$ for 1.5 months. No obvious difference can be observed compared with the as received H131 sample (Fig. 3(a)). While the EDS maps (Fig. 4(b)) reveal that precipitates have already formed on pre-existing particles. The thin lamellar precipitate formed on the end of the needle-shaped pre-existing particle (rich in Mn and Fe) is rich in $\mathrm{Mg}$ and Si (indicated by arrows), which could be a $\mathrm{Mg}_{2}$ Si-type [39-41] precipitate. While the plate-shaped pre-existing particle (rich in Cr, indicated by a dash circle) worked as a heterogeneous nucleation site for the globular Mg-rich precipitate (indicated by a dash arrow, 13.5 at.\% Mg). EDS maps of the 9 months’ sample (Fig. 4(d)) demonstrate that larger Mg-rich precipitates have formed on the $\mathrm{Al}_{6}(\mathrm{Mn}, \mathrm{Fe}, \mathrm{Cr})$-type pre-existing particles. Furthermore, some tiny Mgrich precipitates (highlighted by arrows in Fig.4 (d)) also nucleate without the help of pre-existing particles. When 
aging time increases to 18 months, precipitates with a darker contrast than the matrix can be observed in the dark field (DF) image (Fig. 4(e)) (highlighted by arrows). The nucleation sites for these precipitates are subgrain boundaries, and EDS maps (Fig. 4(f)) illustrate that these precipitates are rich in Mg. Fig. 4(g) shows the DF image of the 30 months' sample. The size of these intragranular precipitates is even larger, and no subgrain boundaries or pre-existing particles are found to associate with the nucleation of these Mg-rich (Fig. 4(f)) precipitates. In addition, no Si rich precipitates are identified in the 9, 18 and 30 months' samples. The average aspect ratio of precipitates is 0.3 (see Table 2). The average size of Mg-rich precipitates of different aging times is determined from STEM images and EDS mapping results, Table 2.

Fig. 5 (a) and (b) are the STEM BF image and the corresponding EDS maps of Al $5083 \mathrm{H} 116$ aged at $70{ }^{\circ} \mathrm{C}$ for 3 months. Mg-rich precipitates are only detected on the end of an $\mathrm{Al}_{6} \mathrm{Mn}$-type pre-existing particle. Large teeth-like $\mathrm{Al}_{6}(\mathrm{Mn}, \mathrm{Fe}, \mathrm{Cr})$-type and (Mn,Fe,Cr,Si)-rich (highlighted by arrows)[42] pre-existing particles were found in $\mathrm{Al}$ 5083 H116 aged at $70{ }^{\circ} \mathrm{C}$ for 9 months, as shown in Fig. 5 (c) and (d). In addition, only one Mg-rich precipitate (indicated by a circle) is observed near the pre-existing particles. While in the 18 months' sample (Fig. 5(e) and (f)), more precipitates were found to form on pre-existing particles, grain boundaries, as well as within the matrix. Moreover, intragranular Mg-rich precipitates were found on dislocations, as highlighted by arrows in Fig. 5(e). The size of the intergranular precipitates is obviously larger than that of the intragranular ones, which could be attributed to the "collector plate” effect of grain boundaries [43]. Even larger (see Table 2) Mg-rich precipitates are found in the 30 months' sample, as shown in Fig. 5(g) and (h). The size and aspect ratio results of precipitates formed in Al 5083 H116 are summarized in Table 2. Fig. 6 shows the precipitate size distribution of Al 5083 H116 aged at $70{ }^{\circ} \mathrm{C}$ for 18 months. The experimental results fit very well $\left(\mathrm{R}_{\text {square }}=0.9966\right)$ using a cumulative lognormal distribution.

The STEM images and EDS maps of Al $5083 \mathrm{H} 116$ aged at $50{ }^{\circ} \mathrm{C}$ for different time are shown in Fig. 7. Mg-rich precipitates were not able to be identified in the 9 months' sample (see Fig. 7 (a) and (b)), but Mg-rich precipitates were observed on pre-existing particles in the 24 months' sample, as shown in Fig. 7 (c) and (d) 
(indicated by a dash circle). After aging at $50{ }^{\circ} \mathrm{C}$ for 41 months (see Fig. 7 (e) and (f)), the size of Mg-rich precipitates formed in $\mathrm{Al} 5083 \mathrm{H} 116$ is only $13.5 \mathrm{~nm}$ (Table 2).

\subsection{Atom Probe Tomography Results}

Mg-rich precipitates were very difficult to reveal using STEM-EDS for Al 5083 H116 aged at $50{ }^{\circ} \mathrm{C}$ for 9 and 24 months, and thus APT was applied as a complementary technique due to the enhanced chemical sensitivity of APT compared to STEM-EDS. Fig. 8(a) displays a 3D reconstruction of an analyzed volume containing $\mathcal{1} 1 \times 10^{7}$ atoms from the $\mathrm{Al} 5083 \mathrm{H} 116$ sample aged at $50{ }^{\circ} \mathrm{C}$ for 24 months, and the results (Fig. 8(a)) indicate this sample consists of two phases and a phase boundary. The 3D atom maps of all elements in the material are displayed in Fig. 8(a). The top region of the APT needle is rich in Al and Mg, which is the matrix of Al 5083 H116 alloy. While the bottom region of the APT needle is comprised of $\mathrm{Al}, \mathrm{Mn}$, Fe, and $\mathrm{Cr}$ with a composition that corresponds to $\mathrm{Al}_{6}(\mathrm{Mn}, \mathrm{Fe}, \mathrm{Cr})$-type pre-existing particles as observed in the STEM EDS results above. Fig. 8(b) and (c) illustrates the 3D morphology of Mg-rich precipitates, which were delineated by 10 at.\% $\mathrm{Mg}$ isoconcentration surfaces. Moreover, a 5 at.\% Mn isoconcentration surface was added to highlight the position of pre-existing particle-matrix interface. Mg-rich precipitates were found in the matrix as well as on the pre-existing particle/matrix interface. Six Mg-rich precipitates of oblate ellipsoid morphology are observed in the matrix, with the magnified view of three precipitates shown in Fig. 8 (d). The size of these precipitates ranges from 2.5 to 6.5 $\mathrm{nm}$ (in radius). However, the morphology of precipitates formed on the pre-existing particle are lamellar (see Fig. 8 (e)). The thickness of these lamellar precipitates is less than $2 \mathrm{~nm}$, and the length of them varies from $1 \mathrm{~nm}$ to 15 nm. The number density of precipitates formed on the pre-existing particle is almost five times of that for precipitates nucleated in the matrix, this could be attributed to the lower energy barrier needed for heterogeneous nucleation. [44]

Fig. 9 (a) illustrates the line scan results of a Mg-rich precipitate formed in the matrix as shown in Fig. 8(d) (indicated by an arrow). The Mg concentration of the precipitate is around 18.3 at.\%, which is very close to the reported concentration of GP zones (19 at.\%).[17] Therefore, these precipitates are most likely GP zones. Mg concentration of one of the lamellar precipitates (see Fig. 8(b) and (e)) formed on the pre-existing particle is 
shown in Fig. 9 (b), and a higher Mg concentration, 24.8 at.\% (average along the thickness direction), is detected. $\beta$ ” phase is reported to have a stoichiometry of $\mathrm{Al}_{3} \mathrm{Mg}$,[21] which is very close to the $\mathrm{Mg}$ concentration (24.8 at.\%) of precipitates in Fig. 8(e). Thus, precipitates formed on pre-existing particles are most likely to be $\beta$ ” phases.

In addition, Fig. 9 (b) reveals that the composition of the pre-existing particle is not uniform. The outside part ( $\sim 5$ $\mathrm{nm}$ in thickness) of the particle (close to the matrix/pre-existing particle interface, indicated by "part 1" in Fig. 9(b)) is rich in Mn, while the inside part of the particle (highlighted by "part 2” in Fig. 9(b)) is rich in Mn, Fe, and Si. One possible explanation is that Al-Mn-Fe-Si-type particles form firstly during the solidification process of Al 5083 alloy, and Si will become depleted quickly because of its low concentration (see Table 1). Subsequently, a layer of $\mathrm{Al}_{6}(\mathrm{Mn})$-type particle starts to form on the Al-Mn-Fe-Si-type particle.

\subsection{Small Angle Neutron Scattering Results}

Fig. 10 displays the scattering cross-section of Al $5083 \mathrm{H} 131$ and H116 alloys in the as-quenched and differently aged states. For both Al $5083 \mathrm{H} 131$ and H116, the as quenched sample shows the lowest scattering intensity, and the scattering intensity decreases with increasing scattering vector $(q)$. After aging at $70{ }^{\circ} \mathrm{C}$ for 1.5 months, a considerable increase in scattering intensity was observed for the Al $5083 \mathrm{H} 131$ alloy sample. A further increase in scattering intensity was identified for $\mathrm{Al} 5083 \mathrm{H} 131$ aged at $70{ }^{\circ} \mathrm{C}$ for 9 months. However, the scattering intensity of $\mathrm{Al} 5083 \mathrm{H} 131$ alloy starts to decreases beyond 9 months in spite of the increase in aging time (18 and 30 months). In addition, the scattering intensity of the 30 months' sample is even slightly lower than that of the 1.5 months’ sample. The scattering intensity results of Al $5083 \mathrm{H} 116$ alloy aged at $70{ }^{\circ} \mathrm{Calso}$ experienced similar kinetics as Al $5083 \mathrm{H} 131$ samples (increases first and then decreases). Whereas, the highest scattering results were achieved at 18 months, which is 9 months later than the Al 5083 H131 sample. The SANS results of the Al $5083 \mathrm{H} 116$ sample aged at $50{ }^{\circ} \mathrm{C}$ are shown in Fig. 10 (c). Even though the scattering intensity increase is not large, a clear increasing trend can still be observed from 9 months to 41 months (see the inserted image in Fig. 10 (c)). 
Based on the two-phase model of isolated particles in a homogeneous matrix[28], the SANS cross-section was calculated as

$$
\frac{d \Sigma}{d \Omega}(q)=\int_{0}^{\infty}(\Delta \eta)^{2} n(R) V^{2}(R)|F(q, R)|^{2} d R
$$

where $\Delta \eta$ is the difference in scattering length densities of precipitate and matrix, $n(R) d R$ stands for the number density of precipitates between $R$ and $R+d R, V(R)$ is the volume of precipitates, and $F(q, R)$ is the form factor. Moreover, the item, $\mathrm{k}_{\mathrm{c}} q^{-4}$, is added considering the effect of sharp interfaces between larger inhomogeneities $\left(\mathrm{Al}_{6} \mathrm{Mn}\right.$ type pre-existing particles in this study) and the matrix. A background, $c$, caused by scattering of compositional fluctuations is also added.

STEM and APT, as complementary techniques, provide valuable information for the quantitative analysis of SANS results. Based on STEM and APT results, the shape of the Mg-rich precipitate is ellipsoid with two semimajor axes of length $R$, and one semi-minor axis of length $(u R)$, where $u$ is the aspect ratio. The values of $u$ for $\mathrm{Al}$ $5083 \mathrm{H} 131$ and H116 are 0.3 and 0.5, respectively. For randomly orientated precipitates, $F(q, R)$ for ellipsoids can be calculated as follow[28]:

$$
|F(q, R)|^{2}=\int_{0}^{\pi / 2}\left[F_{s}\left(q, R \sqrt{\cos ^{2} \theta+u^{2} \sin ^{2} \theta}\right)\right]^{2} \cos \theta d \theta
$$

with

$$
F_{s}(q, R)=3 \frac{\sin (q R)-q R \cos (q R)}{(q R)^{3}}
$$

where $F_{s}(q, R)$ is the form factor for spherical particles of radius $R$. The particle size distribution, $n(R)$, is described by log-normal distribution (see Fig. 6) functions:

$$
n(R)=\frac{n_{0}}{\sqrt{2 \pi} \sigma R} \exp \left(-\frac{\left(\ln \left(R / R_{a}\right)\right)^{2}}{2 \sigma^{2}}\right)
$$


where $n_{0}$ is the number density, $\sigma$ is the width of the distribution, and $R_{\mathrm{a}}$ is the average radius of the precipitate. The difference in scattering length densities $\Delta \eta$ is given by:

$$
\Delta \eta=\left|\eta_{p}-\eta_{m}\right|=\left|\sum x_{i}^{p} b_{i} / v_{i}-\sum x_{i}^{m} b_{i} / v_{i}\right|
$$

where $\eta_{\mathrm{p}}$ and $\eta_{\mathrm{m}}$ are the average scattering length density of the precipitate and the matrix. $b$ is the scattering length of individual elements, $x$ is the atomic fraction, and the atomic volume is denoted by $v$. The coherent scattering length of $\mathrm{Al}$ and $\mathrm{Mg}$ are $0.3449 \times 10^{-12} \mathrm{~cm}$ and $0.5375 \times 10^{-12} \mathrm{~cm}$ respectively[45]. During the fitting of SANS results, a constant $\Delta \eta$ was assumed at first. However, the scattering intensities of $\mathrm{Al} 5083 \mathrm{H} 131\left(70{ }^{\circ} \mathrm{C}\right)$ keep increasing with aging time, as shown by the dash lines in Fig. 10 (a). Therefore, a variable $\Delta \eta$ must be applied to explain the decrease in scatting intensities of $\mathrm{Al} 5083 \mathrm{H} 131$ and $\mathrm{H} 116$ aged at $70{ }^{\circ} \mathrm{C}$

The Mg concentration of precipitates in Al 5083 H131 and H116 aged at different temperatures for different times obtained from STEM-EDS and APT are shown in Fig. 11. In order to obtain the Mg concentration, a line scan is run across each precipitate, and the Mg concentration of the corresponding precipitate is equal to the calculated average Mg concentration (averaged over the size of the precipitate). Mg concentrations of the precipitates are found to increase with aging time. For example, when aged at $70{ }^{\circ} \mathrm{C}$ the average $\mathrm{Mg}$ concentration (shown as diamonds in Fig. 11) of precipitates in the 1.5 months' Al $5083 \mathrm{H} 131$ alloy sample is only 14.1 at.\% , while it increases to 32.3 at.\% in the 30 months' sample. The concentration of Mg for GP zones, $\beta$ ”, $\beta$ ', and $\beta$ phases are shown in Table 3. The increase of average Mg concentration indicates the phase transformation from GP zones to $\beta^{\prime} / \beta$ phase. The corresponding scattering length density, $\eta$, calculated using Eq. (5) is also listed in Table 3. From GP zone to $\beta$ " phase, $\Delta \eta$ increases, while from $\beta$ ” phase to $\beta$ ' and $\beta$ phase it decreases.

The modeling results of SANS (solid lines) are shown in Fig. 10, which agree well with experimental results. Moreover, the scattering intensity results of the AQ samples (both Al 5083 H131 and H116) show a linear relationship with $q^{-4}$, which is also known as the Porod law[46]. This relationship could be explained by scattering caused by the sharp interface between $\mathrm{Al}_{6} \mathrm{Mn}$-type pre-existing particles and the matrix. The results of SANS experiments are summarized in Table 4. Radius of Mg-rich precipitates increase with aging time, which is 
consistent with the STEM results. In addition, for Al $5083 \mathrm{H} 131$ and $\mathrm{H} 116$ aged at $70{ }^{\circ} \mathrm{C}$ for 30 months, the precipitate radius in Al $5083 \mathrm{H} 131$ is larger than that in the H116 sample. Despite the relatively long aging time (41 months) at $50{ }^{\circ} \mathrm{C}$, the average radius of precipitates is much smaller than that of $\mathrm{Al} 5083 \mathrm{H} 116$ aged at $70{ }^{\circ} \mathrm{C}$ for 30 months. The number density of precipitates decreases with aging time, Table 4.

\section{Discussions}

\subsection{Coarsening of Mg-rich precipitates}

STEM and SANS results (see Table 2 and 4) reveal that the radius of Mg-rich precipitates increases with aging time at 50 and $70{ }^{\circ} \mathrm{C}$ for both $\mathrm{Al} 5083 \mathrm{H} 131$ and $\mathrm{H} 116$ alloy. While the precipitate number density decreases with aging time, indicating coarsening occurs in both alloys. For spheroid precipitates of a fixed aspect ratio $(\mu)$, the mean precipitate radius $(\bar{R})$ follows the Lifshitz-Slyozov-Wagner theory $[47,48]$ in the coarsening stage, and if the bulk diffusion of $\mathrm{Mg}$ is predominant, the coarsening rate is given as:

$$
\bar{R}^{3}-\bar{R}_{0}^{3}=k_{C O} t
$$

While if the diffusion of $\mathrm{Mg}$ is through the pipe diffusion mechanism related to dislocations,[49] the coarsening rate is therefore

$$
\bar{R}^{5}-\bar{R}_{0}^{5}=k_{C O} t
$$

where $\bar{R}_{0}$ is the mean radius of precipitate $t=0$ (start time of coarsening). $k_{\mathrm{CO}}$ is the associated rate constant, which can be written as[44]

$$
k_{C O} \propto D_{e f f} \gamma X_{e}
$$

where $D_{\text {eff }}$ is the effective diffusion coefficient of $\mathrm{Mg}, \gamma$ is the interfacial energy, and $X_{\mathrm{e}}$ is the equilibrium concentration of $\mathrm{Mg}$ in the matrix at the aging temperature.

Fig. 12(a) shows the precipitate radius versus aging time. The fitting time was chosen to start from 9 months to decrease the effect of the growth stage. The fitting results reveal that the coarsening rate for Al $5083 \mathrm{H} 131\left(t^{0.225}\right)$ 
and $\mathrm{H} 116\left(t^{0.231}\right)$ aged at $70^{\circ} \mathrm{C}$ is very close, which is smaller than that of the pure bulk diffusion scenario but slightly larger than that of the pure pipe diffusion condition. Therefore, it is most likely that the diffusion of Mg related to dislocations is dominant in $\mathrm{Al} 5083 \mathrm{H} 131$ and $\mathrm{H} 116$ aged at $70{ }^{\circ} \mathrm{C}$. In addition, the $k_{\mathrm{CO}}$ value of $\mathrm{Al} 5083$ $\mathrm{H} 131\left(k_{\mathrm{CO}}=22.5\right)$ is 1.8 times of that for $\mathrm{Al} 5083 \mathrm{H} 116\left(k_{\mathrm{CO}}=12.5\right)$ aged at $70{ }^{\circ} \mathrm{C}$. Moreover, the values of $\gamma$ and $X_{\mathrm{e}}$ for $\mathrm{Al} 5083 \mathrm{H} 131$ and $\mathrm{H} 116$ aged at the same temperature are the same. Therefore, $D_{\text {eff }}$ of $\mathrm{Mg}$ in $\mathrm{Al} 5083 \mathrm{H} 131$ is 1.8 times of that in $\mathrm{Al} 5083 \mathrm{H} 116$ at $70{ }^{\circ} \mathrm{C}$. Fig. 12(b) depicts the evolution of precipitate number density, which decreases as $t^{-0.91 \pm 0.14}$ for $\mathrm{Al} 5083 \mathrm{H} 131$ aged at $70{ }^{\circ} \mathrm{C}$, and $t^{-1.11 \pm 0.16}$ for $\mathrm{Al} 5083 \mathrm{H} 116$ aged at $70{ }^{\circ} \mathrm{C}$. The error in the exponent is determined from the nonlinear multivariable regression of the experimental results. The fitting results are in good agreement with the LSW model's prediction of $t^{-1}$.[48]

Even though the mean radius of precipitate is proportional to the cube root of aging time and the precipitate number density decreases as $t^{-1}$, it is not sufficient to predict the start of coarsening as stated by Perez et al..[50] The particle size distribution (PSD) results of Mg-rich precipitates obtained from SANS are displayed in Fig. 13. For $\mathrm{Al} 5083 \mathrm{H} 131$ and $\mathrm{H} 116$ aged at 70C, enough small precipitates (radius, $\bar{R}$, is small) have been generated after 18 months to initiate coarsening, see Fig. 13 (a) and (b), which is consistent with the conclusion of Fig. 12. However, PSD results (9 and 24 months) of $\mathrm{Al} 5083 \mathrm{H} 116$ aged at $50^{\circ} \mathrm{C}$ reveal that small particles are not enough to establish the start of coarsening.[51]

\subsection{Phase transformation sequence}

The precipitate sequence of Mg-rich precipitates is affected by aging temperature, Mg concentration in the matrix, and aging time. $\beta$ ' and $\beta$ phase are reported to form at high temperatures $\left(>150^{\circ} \mathrm{C}\right)[14]$, while given enough aging time (12 months) $\beta$ ' and $\beta$ phases were also observed to form at $70{ }^{\circ} \mathrm{C}$ in Al 5083 alloy[19]. Moreover, TEM and differential scanning calorimetry (DSC) [21,23] results indicated that GP zones will form before the appearance of $\beta$ ” phase in a matrix of relatively low Mg concentration ( $<14 \mathrm{wt} . \%)$, and both GP zones and $\beta$ ” phase can form below $80{ }^{\circ} \mathrm{C}[23]$. In the present study, the $\mathrm{Mg}$ concentration is 5.25 at.\%, the aging temperature is 50 and 90 and the aging time is as long as 41 and 30 months, respectively. Therefore, GP zone, $\beta$ ’, $\beta$, and $\beta$ phase are able 
to form in $\mathrm{Al} 5083$ alloy. In reality, the presence of GP zones and $\beta$ ” phases in $\mathrm{Al} 5083 \mathrm{H} 116$ sample aged at $50{ }^{\circ} \mathrm{C}$ has been confirmed by APT results, which is consistent with our previous results of Al 5456 H116 obtained from high resolution TEM and STEM EDS.[52]

Table 3 reveals that, from GP zone to $\beta$ " phase, the value of $\Delta \eta$ increases. While form $\beta$ " phase to $\beta^{\prime} / \beta$ phase, it decreases. For Al $5083 \mathrm{H} 131$ and H116 samples aged at $\mathbf{7} \mathfrak{C}$, the scattering intensity increases first and then decreases (see Fig. 10 (a) and (b)). The increase of scatting intensity in both alloys can be attributed to the increase of precipitate radius and the value of $\Delta \eta$, while the decrease of scattering intensity difference $(\Delta \eta)$ can be applied to explain the decrease of scattering intensity. Therefore, it is most likely that the equilibrium phase transformation from GP zones, to $\beta^{\prime \prime}$, and $\beta$ ’/ $\beta$ phase happens in $\mathrm{Al} 5083 \mathrm{H} 131$ and $\mathrm{H} 116$ aged at $70{ }^{\circ} \mathrm{C}$.

\subsection{Effects of different tempers}

Al 5083 H131 (3/8 of full hardness) experiences more cold working than Al 5083 H116 (1/8 of full hardness),[29] which was confirmed by the micro hardness of these two alloys. In addition, EBSD reveals that GND density (Fig. 2) of $\mathrm{Al} 5083 \mathrm{H} 131$ is 1.6 times of that in Al 5083 H116. STEM (Fig. 4, Table 2) and SANS (Fig. 5, Table 4) results show that less Mg-rich precipitates are formed in $\mathrm{Al} 5083 \mathrm{H} 116$ than in H131, and the radius of these precipitates are smaller at the same aging states (for instance, $70{ }^{\circ} \mathrm{C}$ for 9,18 , and 30 months).

The precipitation of Mg-rich precipitates (GP zone, $\beta$ ”, $\beta$ ', and $\beta$ phase) is a diffusion controlled process, and Mg is the diffusion rate limiting element. Dislocations have been reported to be favorable nucleation sites for precipitation and potentially provide rapid diffusion paths for solute atoms.[44] On the one hand, the higher dislocation density in Al 5083 H131 provides more heterogeneous nucleation sites (see Fig. 4(e) and Fig. 5(e)), leading to the higher precipitate number density in Al 5083 H131. On the other hand, the pipe diffusion effect [53] of dislocation can highly facilitate the growth of $\beta$ 'phase, which has been observed in previous studies[19,38]. Hart [54] proposed a simple way to estimate the effective diffusion coefficient, $D_{\text {eff }}$, caused by dislocations as follows 


$$
D_{\text {eff }}=\left(1-f_{d}\right) D_{\text {bulk }}+f_{d} D_{d}
$$

where $f_{\mathrm{d}}$ is the fraction of dislocation, $D_{\text {bulk }}$ and $D_{\mathrm{d}}$ are the diffusion coefficients of $\mathrm{Mg}$ in the $\mathrm{Al}$ matrix and dislocation cores. $f_{\mathrm{d}}$ can be calculated from dislocation density and the area of dislocation core. Taking the dislocation along the $\{111\}$ plane as an example, the radius of the dislocation core ranges from 0.35 to $1.4 \mathrm{~nm}$ [55]. Atomic simulation reveals that the activation energy of Mg atom in the dislocation core is about 75\% [56]of that in the bulk $(Q=-112.5 \mathrm{~kJ})[57]$. The GND density $\left(5.33 \times 10^{13} \mathrm{~m}^{-2}\right.$ for H131, and $3.28 \times 10^{13} \mathrm{~m}^{-2}$ for H116) is used to roughly estimate the relative dislocation density ratio. Based on Eq. (9), $D_{\text {eff }}$ of H131 to that of H116 is about 1.5 at $70{ }^{\circ} \mathrm{G}$ which is very close to the result (1.8) obtained from Fig. 12. Henceforth, a relative slower precipitate growth rate as well as a smaller precipitate radius will be expected in Al 5083 H116.

\subsection{Effects of different aging temperatures}

For Al 5083 H116, different aging temperatures lead to a large difference in the precipitation behavior (see Table 2, Table 4, Fig. 12 and 13). A higher aging temperature means more atoms are able to overcome the energy barrier for nucleation, thus more precipitates are found in the $70{ }^{\circ} \mathrm{C}$ aged $\mathrm{Al} 5083 \mathrm{H} 116$ sample. Moreover, the diffusion coefficient of $\mathrm{Mg}$ atoms at $70{ }^{\circ} \mathrm{C}$ is 10 times of that at $50{ }^{\circ} \mathrm{C}(Q=-112.5 \mathrm{~kJ})[57]$. Therefore, the smaller precipitate size can be explained in the same way above (different temper effects). SANS results reveal that no decrease in neutron scattering intensity is identified for Al $5083 \mathrm{H} 116$ aged at $50^{\circ} \mathrm{C}$ for 41 months, which could be attributed to the fact that phase transformation from $\beta$ ” to $\beta$ ' $/ \beta$ did not finished in Al $5083 \mathrm{H} 16$ aged at $50{ }^{\circ} \mathrm{C}$ for 41 months. Whereas, a higher temperature may cause recrystallization of cold-worked alloy and the reduction of dislocations. Oguocha et al.[58] aged Al 5083 H116 alloys at different temperatures, and found that obvious recrystallization happened at temperatures higher than $175{ }^{\circ} \mathrm{C}$. Henceforth, $70{ }^{\circ} \mathrm{C}$ is not high enough to caused recrystallization and a large decrease in dislocation density.

\subsection{Different nucleation sites}

STEM and EDS results reveal that Mg-rich precipitates first form on heterogeneous sites such as the surface of pre-existing particle, dislocations, and grain boundaries. The relatively low activation energy for nucleation of 
these sites is used to explain the preference [59]. The higher Mg concentration of precipitate formed on preexisting particle can be explained similarly by the "collector plate" mechanism for intergranular precipitates.[51,60] APT results show that the shape of precipitates on the surface of pre-existing particle is different from that in the matrix. Considering that the $\beta$ ” phase is coherent with $\mathrm{Al}$ matrix[23], one possible reason for this difference is that the diffusion coefficient of $\mathrm{Mg}$ at the $\beta$ " phase-matrix interface is close to that of Mg in the matrix, when an elongated precipitate shape will be expected [43].

\section{Conclusions}

Al 5083 alloys of different tempers (H131 and H116) were aged at different temperatures, and EBSD, STEM, APT and SANS were used to characterize the precipitation behavior in these alloys. The main findings are summarized as follows:

1. EBSD results show that $\mathrm{Al} 5083 \mathrm{H} 131$ has smaller grain size and higher average GND density than that of Al 5083 H116. STEM and SANS results reveal that the radius of Mg-rich precipitates formed in Al 5083 H131 and H116 aged at 50 and $70{ }^{\circ} \mathrm{C}$ increases with aging time, while the precipitate number density decreases with time. Particle size distribution results indicate that coarsening of Mg-rich precipitates happens in Al 5083 H131 and H116 aged at $70{ }^{\circ} \mathrm{C}$ for more than 9 months.

2. APT results of $\mathrm{Al} 5083 \mathrm{H} 116$ aged at $50^{\circ} \mathrm{C}$ for 24 months demonstrate that ellipsoid GP zo nes and laminar $\beta$ ” phases formed in the matrix and at the matrix-pre-existing particle interface, respectively.

3. Mg concentration of precipitate increases with aging time and SANS results increase and then decrease with aging time for both $\mathrm{Al} 5083 \mathrm{H} 131$ and $\mathrm{H} 116$ aged at 70C, indicating a phase transformation from GP zones to $\beta^{\prime} / \beta$ phases occurs in both alloys aged at $70{ }^{\circ} \mathrm{C}$

4. Al 5083 alloy of temper H131 has more and larger precipitates than Al $5083 \mathrm{H} 116$ when aged at $70{ }^{\circ} \mathrm{C}$ for the same time (for example, 30 months), which is explained by the higher dislocation density and the larger Mg diffusion coefficient in Al 5083 H131. 
5. A higher aging temperature $\left(70{ }^{\circ} \mathrm{C}\right.$ ) leads to more and larger precipitates in $\mathrm{Al} 5083 \mathrm{H} 116$, and the phase transformation from $\beta^{\prime \prime}$ to $\beta^{\prime} / \beta$ is not complete in $\mathrm{Al} 5083 \mathrm{H} 116$ aged at $50{ }^{\circ} \mathrm{C}$ for 41 months

\section{Acknowledgements}

The work is supported by Office of Naval Research, Award Number: N000141210507. APT and STEM-EDS was conducted at the Center for Nanophase Materials Sciences, which is a DOE Office of Science User Facility. This work utilizes the Oak Ridge National Laboratory's High Flux Isotope Reactor, which is sponsored by the Scientific User Facilities Division, Office of Basic Energy Sciences, U.S. Department of Energy. This work made use of University of Utah USTAR shared facilities support, in part, by the MRSEC Program of NSF under Award No. DMR-1121252. 


\section{References}

[1] R.A. Sielski, Research needs in aluminum structure, Ships Offshore Struct. 3 (2008) 57-65. doi:10.1080/17445300701797111.

[2] E.H. DIX, W.A. ANDERSON, M.B. SHUMAKER, Influence of Service Temperature On the Resistance of Wrought Aluminum-Magnesium Alloys to Corrosion, Corrosion. 15 (1959) 19-26. doi:10.5006/00109312-15.2.19.

[3] J.L. Searles, P.I. Gouma, R.G. Buchheit, Stress Corrosion Cracking of Sensitized AA5083 (Al-4.5Mg-1.0Mn), Mater. Sci. Forum. 396-402 (2002) 1437-1442. doi:10.4028/www.scientific.net/MSF.396-402.1437.

[4] R.H. Jones, D.R. Baer, M.J. Danielson, J.S. Vetrano, Role of $\mathrm{Mg}$ in the stress corrosion cracking of an Al-Mg alloy, Metall. Mater. Trans. a-Physical Metall. Mater. Sci. 32 (2001) 1699-1711. doi:10.1007/s11661-0010148-0.

[5] J. Yan, N.M. Heckman, L. Velasco, A.M. Hodge, Improve sensitization and corrosion resistance of an Al-Mg alloy by optimization of grain boundaries, Sci. Rep. 6 (2016) 26870. doi:10.1038/srep26870.

[6] N. Birbilis, R.G. Buchheit, Electrochemical Characteristics of Intermetallic Phases in Aluminum Alloys, J. Electrochem. Soc. 152 (2005) B140. doi:10.1149/1.1869984.

[7] A. Alil, M. Popović, T. Radetić, M. Zrilić, E. Romhanji, Influence of annealing temperature on the baking response and corrosion properties of an Al-4.6 wt\% Mg alloy with $0.54 \mathrm{wt} \% \mathrm{Cu}$, J. Alloys Compd. 625 (2015) 76-84. doi:10.1016/j.jallcom.2014.11.063.

[8] J. Seong, F. Yang, F. Scheltens, G.S. Frankel, N. Sridhar, Influence of the Altered Surface Layer on the Corrosion of AA5083, J. Electrochem. Soc. 162 (2015) C209-C218. doi:10.1149/2.0321506jes.

[9] M.L.C. Lim, R.G. Kelly, J.R. Scully, Overview of Intergranular Corrosion Mechanisms, Phenomenological Observations, and Modeling of AA5083, Corrosion. 72 (2015) 198-220. doi:10.5006/1818.

[10] C. Gault, A. Dauger, P. Boch, Decomposition of aluminium-magnesium solid solutions studied by ultrasonic measurements of elastic properties and electron microscopy, Acta Metall. 28 (1980) 51-60. doi:10.1016/0001-6160(80)90040-1.

[11] R. Nozato, S. Ishihara, Calorimetric study of precipitation process in Al-Mg Alloys, Trans. Japan Inst. Met. 21 (1980) 580-588. doi:10.2320/matertrans1960.21.580.

[12] T. Sato, Y. Kojima, T. Takahashi, Modulated structures and GP Zones in Al-Mg Alloys, Metall. Trans. A. 13 (1982) 1373-1378. doi:10.1007/BF02642874.

[13] M. Bouchear, D. Hamana, T. Laoui, GP zones and precipitate morphology in aged Al-Mg alloys, Philos. Mag. A. 73 (1996) 1733-1740. doi:10.1080/01418619608243010.

[14] M.J. Starink, A.-M. Zahra, $\beta^{\prime}$ and $\beta$ precipitation in an Al-Mg alloy studied by DSC and TEM, Acta Mater. 46 (1998) 3381-3397. doi:10.1016/S1359-6454(98)00053-6.

[15] D. Hamana, M. Bouchear, M. Betrouche, A. Derafa, N.Y. Rokhmanov, Comparative study of formation and transformation of transition phases in Al-12 wt.\% Mg alloy, J. Alloys Compd. 320 (2001) 93-102. doi:10.1016/S0925-8388(01)00923-9.

[16] M. Roth, J.M. Raynal, IUCr, Small-angle neutron scattering by Guinier-Preston zones in Al-Mg alloys, J. Appl. Crystallogr. 7 (1974) 219-221. doi:10.1107/S0021889874009320. 
[17] J.M. Raynal, M. Roth, IUCr, Neutron small-angle scattering in aged Al-Mg, J. Appl. Crystallogr. 8 (1975) 535-537. doi:10.1107/S002188987501120X.

[18] R. Goswami, G. Spanos, P.S. Pao, R.L. Holtz, Precipitation behavior of the ß phase in Al-5083, Mater. Sci. Eng. A. 527 (2010) 1089-1095. doi:http://dx.doi.org/10.1016/j.msea.2009.10.007.

[19] Y. Zhu, D.A. Cullen, S. Kar, M.L. Free, L.F. Allard, Evaluation of Al3Mg2 precipitates and Mn-rich phase in aluminum-magnesium alloy based on scanning transmission electron microscopy imaging, Metall. Mater. Trans. A Phys. Metall. Mater. Sci. 43 (2012) 4933-4939. doi:10.1007/s11661-012-1354-7.

[20] G. Yi, J.D. Poplawsky, D.A. Cullen, Z. Wang, M.L. Free, Characterization and Modeling the Precipitation of Mg-rich Phases in Al 5xxx Alloys Aged at Low Temperatures, J. Mater. Sci. Technol. (2017) Submitted.

[21] K. Osamura, T. Ogura, Metastable phases in the early stage of precipitation in Al-Mg alloys, Metall. Trans. A. 15 (1984) 835-842. doi:10.1007/BF02644557.

[22] M. Feuerbacher, C. Thomas, E. Al., The Samson phase, $\beta-M g 2 A l 3$, revisited, Zeitschrift Fur Krist. 222 (2007) 259-288. doi:10.1524/zkri.2007.222.6.259.

[23] T. Sato, A. Kamio, High resolution electron microscopy of phase decomposition microstructures in aluminium-based alloys, Mater. Sci. Eng. A. 146 (1991) 161-180. doi:10.1016/0921-5093(91)90275-R.

[24] M.K. Miller, Atom Probe Tomography: Analysis at the Atomic Level, Springer US, 2000.

[25] I. Timokhina, M.K. Miller, J. Wang, H. Beladi, P. Cizek, P.D. Hodgson, On the Ti-Mo-Fe-C atomic clustering during interphase precipitation in the Ti-Mo steel studied by advanced microscopic techniques, Mater. Des. 111 (2016) 222-229. doi:http://dx.doi.org/10.1016/j.matdes.2016.08.086.

[26] H. Aboulfadl, J. Deges, P. Choi, D. Raabe, Dynamic strain aging studied at the atomic scale, Acta Mater. 86 (2015) 34-42. doi:10.1016/j.actamat.2014.12.028.

[27] X. Sauvage, N. Enikeev, R. Valiev, Y. Nasedkina, M. Murashkin, Atomic-scale analysis of the segregation and precipitation mechanisms in a severely deformed Al-Mg alloy, Acta Mater. 72 (2014) 125-136. doi:10.1016/j.actamat.2014.03.033.

[28] A. Guinier, G. Fournet, Small-angle scattering of X-rays, Wiley, New York, 1955.

[29] J.G. Kaufman, a S.M. International, Introduction to Aluminum Alloys and Tempers, 2000.

[30] S. Kar, Measuring and Modeling of Thermal Exposure Corrosion Damage Susceptibility of AA5083 Alloy, Department of Metallurgical Engineering, University of Utah, 2012.

[31] J.F. Nye, Some geometrical relations in dislocated crystals, Acta Metall. 1 (1953) 153-162. doi:http://dx.doi.org/10.1016/0001-6160(53)90054-6.

[32] C. Zhu, T. Harrington, V. Livescu, G.T. Gray III, K.S. Vecchio, Determination of geometrically necessary dislocations in large shear strain localization in aluminum, Acta Mater. 118 (2016) 383-394.

doi:http://dx.doi.org/10.1016/j.actamat.2016.07.051.

[33] L.S. Toth, C.F. Gu, B. Beausir, J.J. Fundenberger, M. Hoffman, Geometrically necessary dislocations favor the Taylor uniform deformation mode in ultra-fine-grained polycrystals, Acta Mater. 117 (2016) 35-42. doi:10.1016/j.actamat.2016.06.062.

[34] M.K. Miller, K.F. Russell, K. Thompson, R. Alvis, D.J. Larson, Review of atom probe FIB-based specimen preparation methods, Microsc. Microanal. 13 (2007) 428-436. doi:10.1017/S1431927607070845. 
[35] K. Thompson, D. Lawrence, D.J. Larson, J.D. Olson, T.F. Kelly, B. Gorman, In situ site-specific specimen preparation for atom probe tomography, Ultramicroscopy. 107 (2007) 131-139.

doi:10.1016/j.ultramic.2006.06.008.

[36] G.D. Wignall, K.C. Littrell, W.T. Heller, Y.B. Melnichenko, K.M. Bailey, G.W. Lynn, D.A. Myles, V.S. Urban, M. V. Buchanan, D.L. Selby, P.D. Butler, The $40 \mathrm{~m}$ general purpose small-angle neutron scattering instrument at Oak Ridge National Laboratory, J. Appl. Crystallogr. 45 (2012) 990-998. doi:10.1107/S0021889812027057.

[37] J. Jiang, T. Benjamin Britton, A.J. Wilkinson, Evolution of intragranular stresses and dislocation densities during cyclic deformation of polycrystalline copper, Acta Mater. 94 (2015) 193-204.

doi:http://dx.doi.org/10.1016/j.actamat.2015.04.031.

[38] R. Goswami, R.L. Holtz, Transmission electron microscopic investigations of grain boundary beta phase precipitation in Al 5083 aged at $373 \mathrm{~K}$ (100 C), Metall. Mater. Trans. A Phys. Metall. Mater. Sci. 44 (2013) 1279-1289. doi:10.1007/s11661-012-1166-9.

[39] O. Engler, S. Miller-Jupp, Control of second-phase particles in the Al-Mg-Mn alloy AA 5083, J. Alloys Compd. 689 (2016) 998-1010. doi:http://dx.doi.org/10.1016/j.jallcom.2016.08.070.

[40] G. Yi, Y. Zhu, D.A. Cullen, A.T. Derrick, M.L. Free, J. Grandfield, Precipitates in long term aging Al 5083 alloy, Light Met. 2014 (2014) 249-253.

[41] G. Yi, D.A. Cullen, A.T. Derrick, Y. Zhu, M.L. Free, Effects of different temper and aging temperature on the precipitation behavior of Al 5xxx alloy, in: TMS Light Met., Minerals, Metals and Materials Society, 2015: pp. 361-365.

[42] Y. Birol, F. Sertcelik, Intermetallic particles in a strip-cast Al-Fe-Mn-Si alloy, Zeitschrift Fuer Met. Res. Adv. Tech. 90 (1999) 329-334.

[43] G. Yi, M.L. Free, Y. Zhu, A.T. Derrick, Capillarity effect controlled precipitate growth at the grain boundary of long-term aging Al 5083 alloy, in: Metall. Mater. Trans. A Phys. Metall. Mater. Sci., Springer Boston, 2014: pp. 4851-4862.

[44] D.A. Porter, K.E. Easterling, Phase Transformations in Metals and Alloys Third Edition, 2014. doi:10.1146/annurev.ms.03.080173.001551.

[45] V.F. Sears, Neutron scattering lengths and cross sections, Neutron News. 3 (1992) 26-37. doi:10.1080/10448639208218770.

[46] S.K. Sinha, E.B. Sirota, S. Garoff, H.B. Stanley, X-ray and neutron scattering from rough surfaces, Phys. Rev. B. 38 (1988) 2297-2311. doi:10.1103/PhysRevB.38.2297.

[47] I.M. Lifshitz, V.V. Slyozov, The kinetics of precipitation from supersaturated solid solutions, J. Phys. Chem. Solids. 19 (1961) 35-50. doi:10.1016/0022-3697(61)90054-3.

[48] C. Wagner, See, for instance, the following references: Z, Elektrochem. 65 (1961) 581.

[49] A.J. Ardell, On the coarsening of grain boundary precipitates, Acta Metall. 20 (1972) 601-609. doi:http://dx.doi.org/10.1016/0001-6160(72)90015-6.

[50] M. Perez, M. Dumont, D. Acevedo-Reyes, Implementation of classical nucleation and growth theories for precipitation, Acta Mater. 56 (2008) 2119-2132. doi:10.1016/j.actamat.2007.12.050. 
[51] G. Yi, A.T. Derrick, Y. Zhu, M.L. Free, A Collector Plate Mechanism-Based Classical Intergranular Precipitation Model for Al Alloys Sensitized at Different Temperatures, Metall. Mater. Trans. A Phys. Metall. Mater. Sci. 46 (2015) 5393-5406.

[52] G. Yi, D.A. Cullen, K.C. Littrell, W. Golumbfskie, E. Sundberg, M.L. Free, Characterization of Al-Mg Alloy Aged at Low Temperatures, Metall. Mater. Trans. a-Physical Metall. Mater. Sci. Submitted (2016).

[53] M. Legros, G. Dehm, E. Arzt, T.J. Balk, Observation of Giant Diffusivity Along Dislocation Cores, Science (80-. ). 319 (2008) 1646-1649. doi:10.1126/science.1151771.

[54] E.W. Hart, On the role of dislocations in bulk diffusion, Acta Metall. 5 (1957) 597. doi:10.1016/00016160(57)90127-X.

[55] T. Hu, K. Ma, T.D. Topping, J.M. Schoenung, E.J. Lavernia, Precipitation phenomena in an ultrafinegrained Al alloy, Acta Mater. 61 (2013) 2163-2178. doi:10.1016/j.actamat.2012.12.037.

[56] R.C. Picu, D. Zhang, Atomistic study of pipe diffusion in Al-Mg alloys, Acta Mater. 52 (2004) 161-171. doi:10.1016/j.actamat.2003.09.002.

[57] J. Yao, Y.-W. Cui, H. Liu, H. Kou, J. Li, L. Zhou, Diffusional mobility for fcc phase of Al-Mg-Zn system and its applications, Calphad. 32 (2008) 602-607. doi:10.1016/j.calphad.2008.04.002.

[58] I.N.A. Oguocha, O.J. Adigun, S. Yannacopoulos, Effect of sensitization heat treatment on properties of Al-Mg alloy AA5083-H116, J. Mater. Sci. 43 (2008) 4208-4214. doi:10.1007/s10853-008-2606-1.

[59] S.G. Kwon, G. Krylova, P.J. Phillips, R.F. Klie, S. Chattopadhyay, T. Shibata, E.E. Bunel, Y. Liu, V.B. Prakapenka, B. Lee, E. V Shevchenko, Heterogeneous nucleation and shape transformation of multicomponent metallic nanostructures, Nat Mater. 14 (2015) 215-223.

[60] G. Yi, Y. Zhu, E. Sundberg, A.T. Derrick, M.L. Free, Sensitization Prediction and Validation for Al 5xxx Alloys Exposed to Long-Term Cyclical and Constant Heating at Low Temperatures, Corrosion. 72 (2015) 177-186. doi:10.5006/1918. 


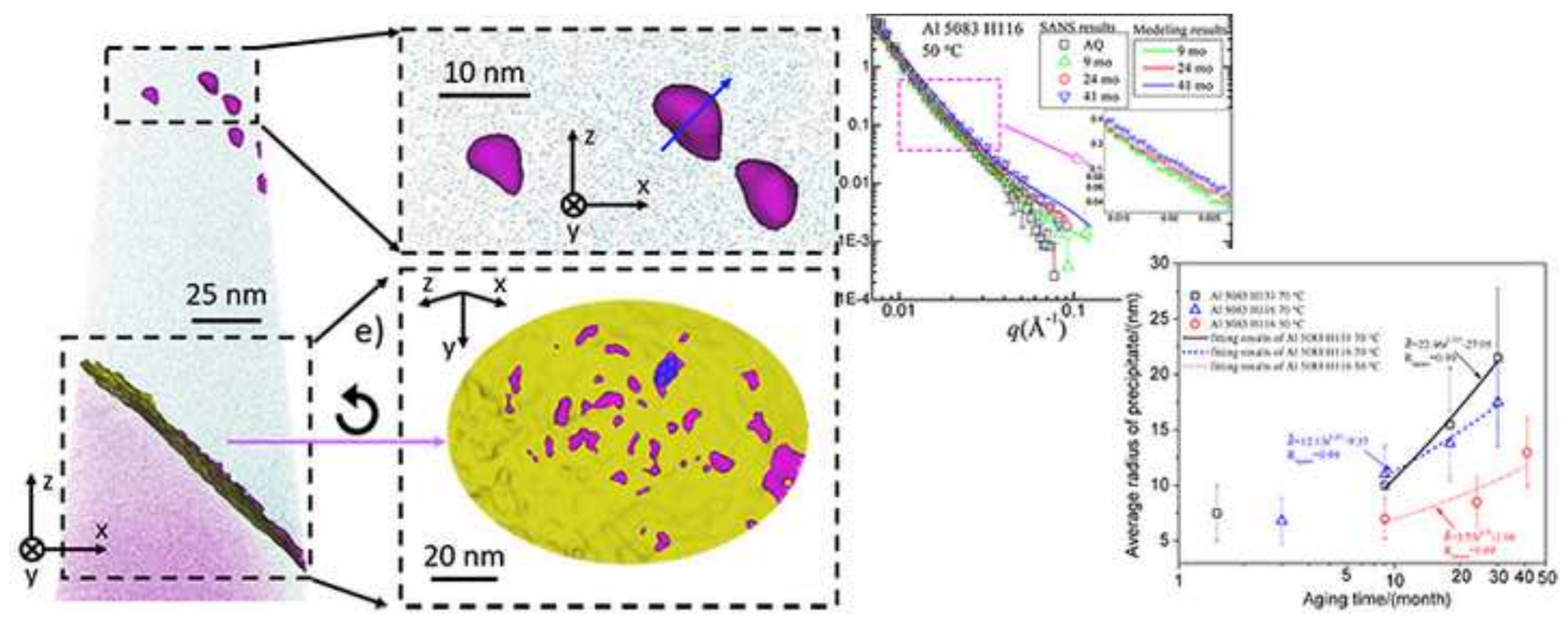




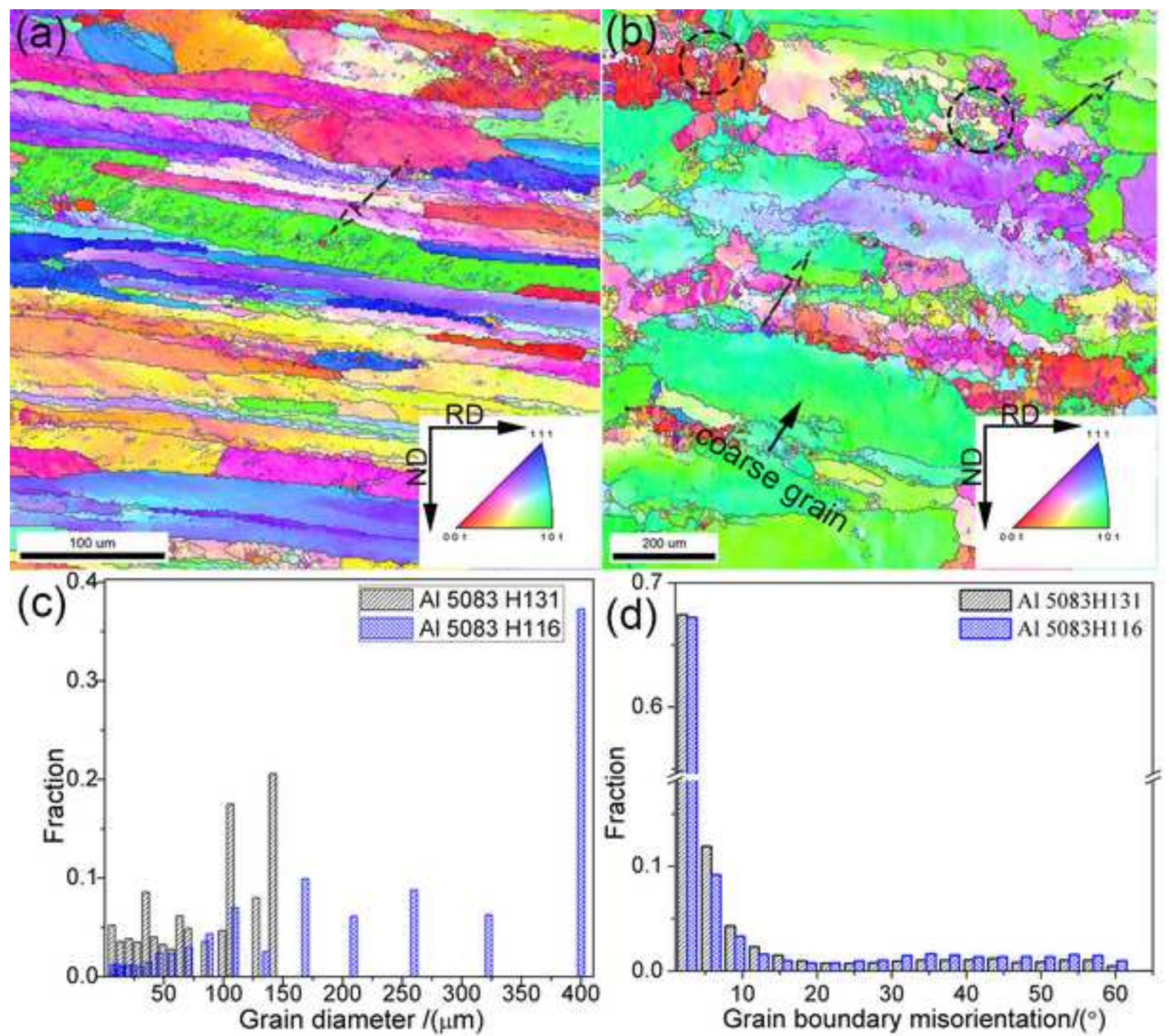




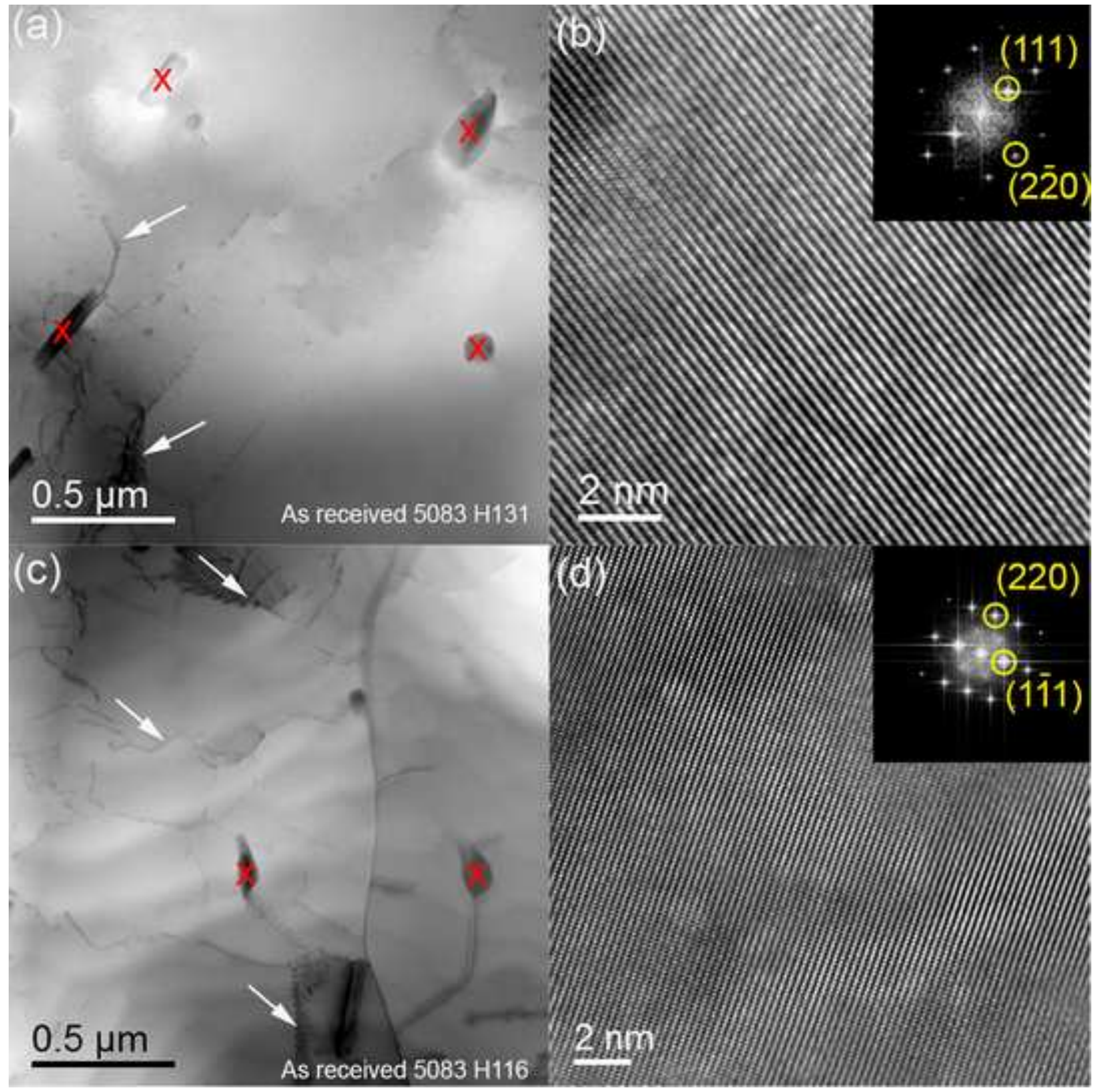




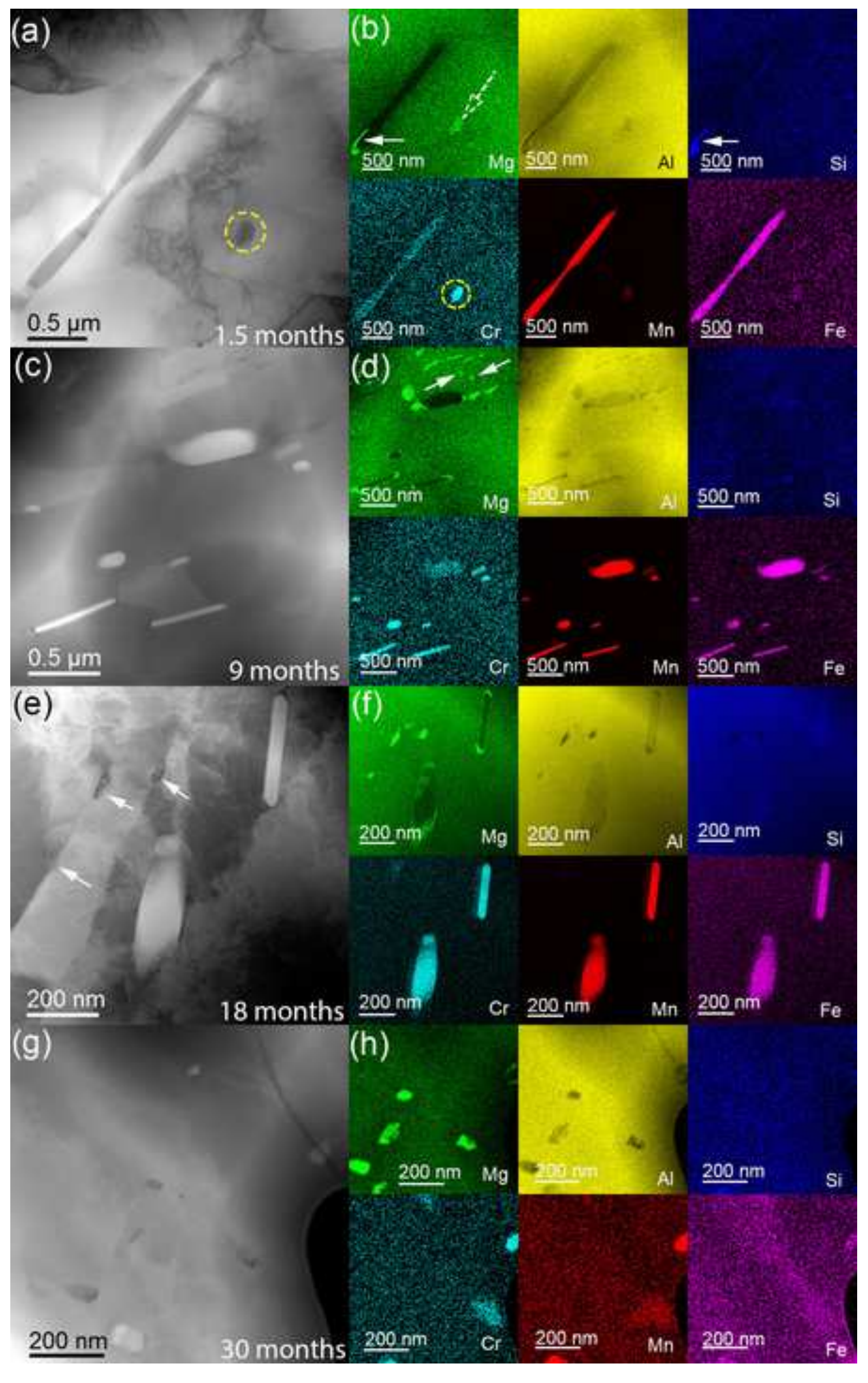

Si

Min




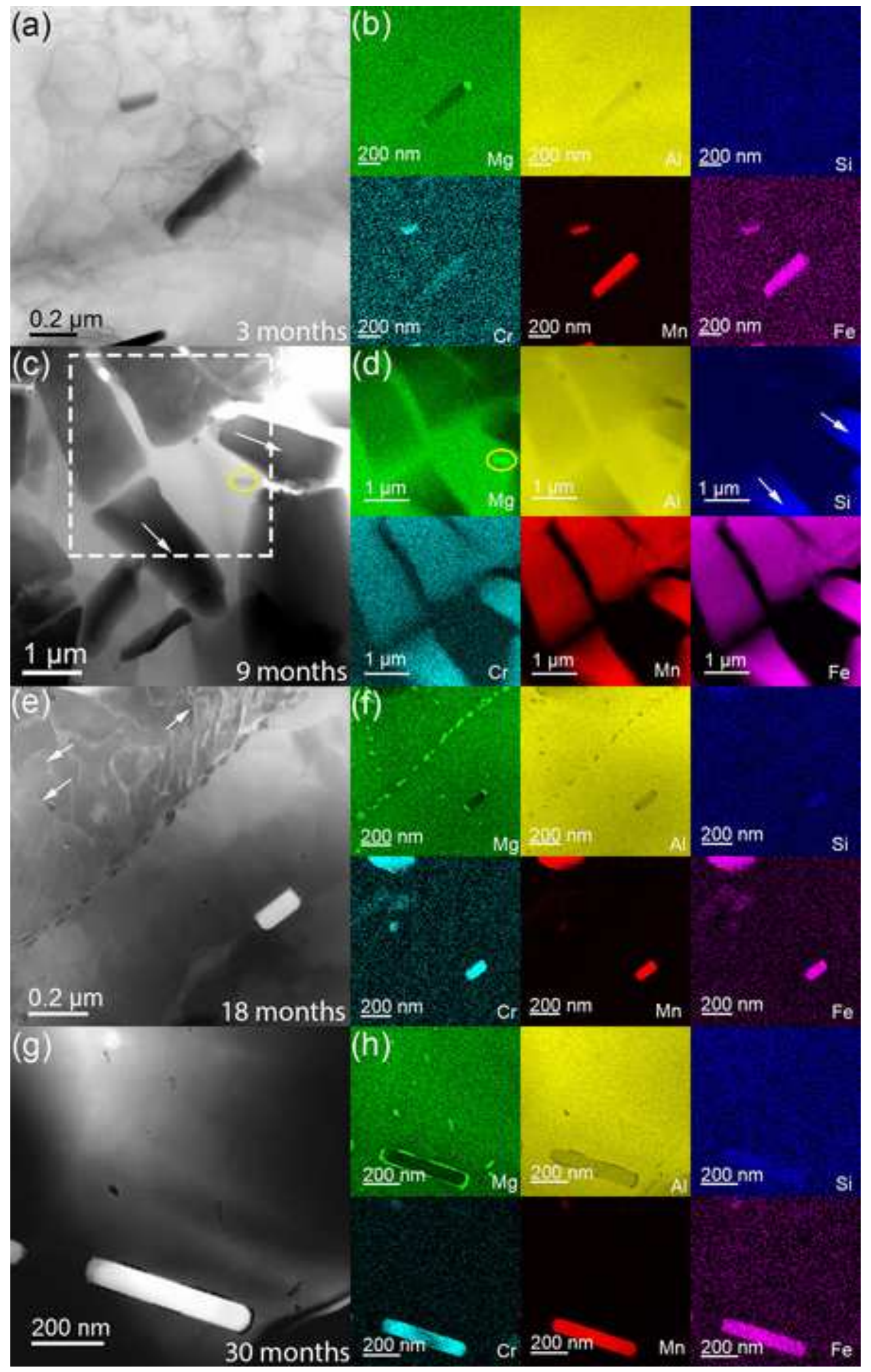




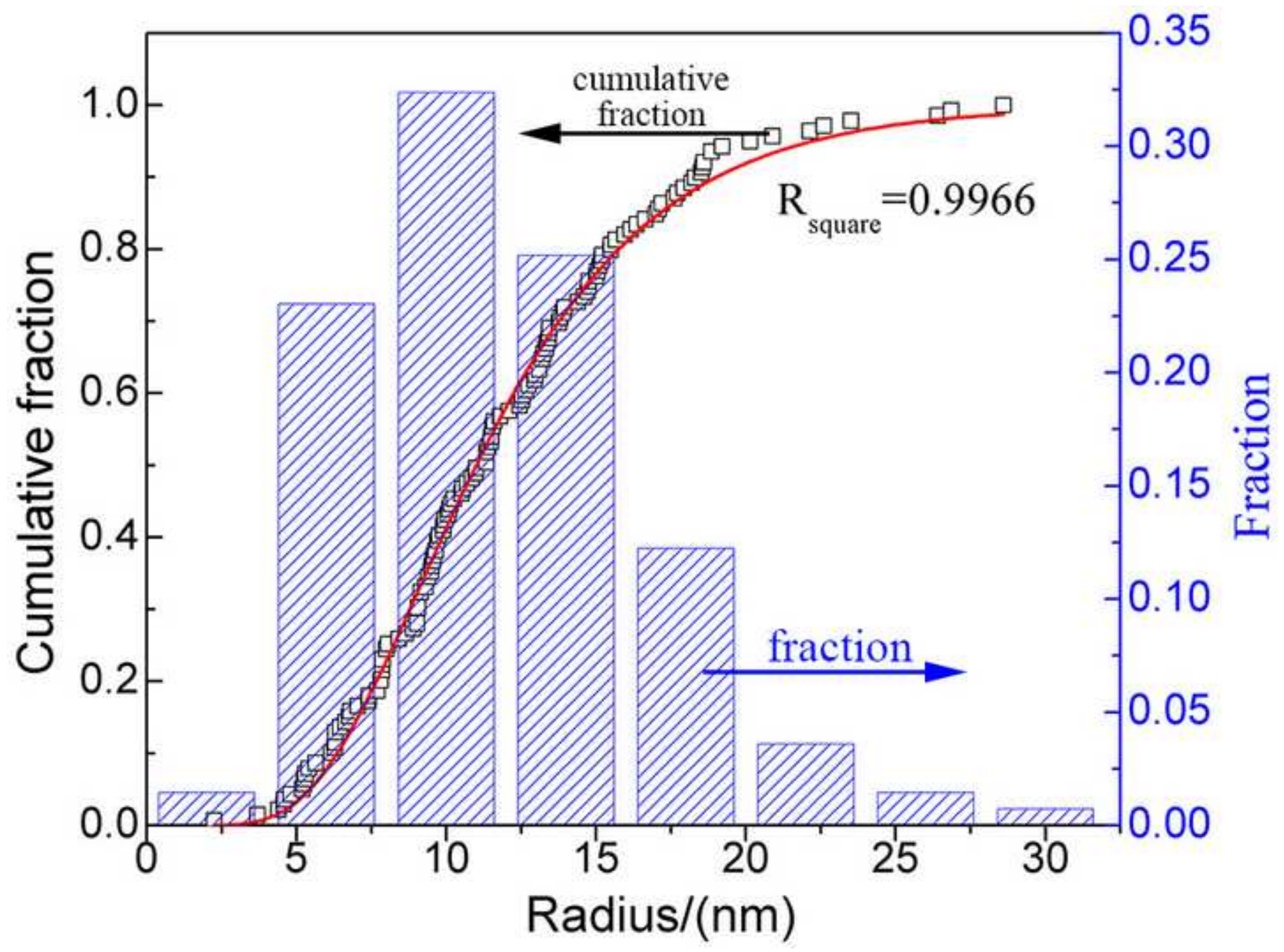




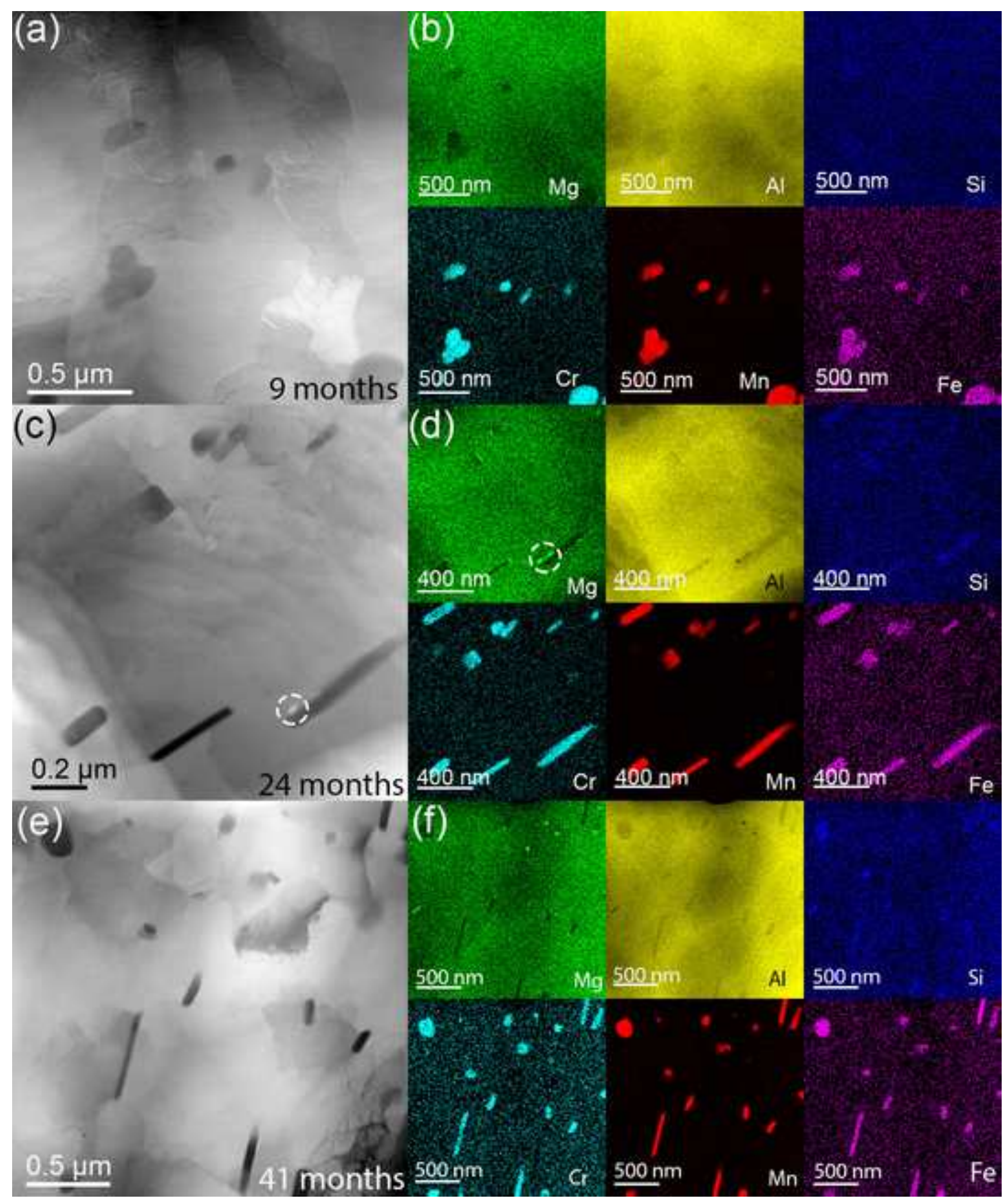

(b)

(d)

(f)

Si

$\mathrm{Fe}$ 


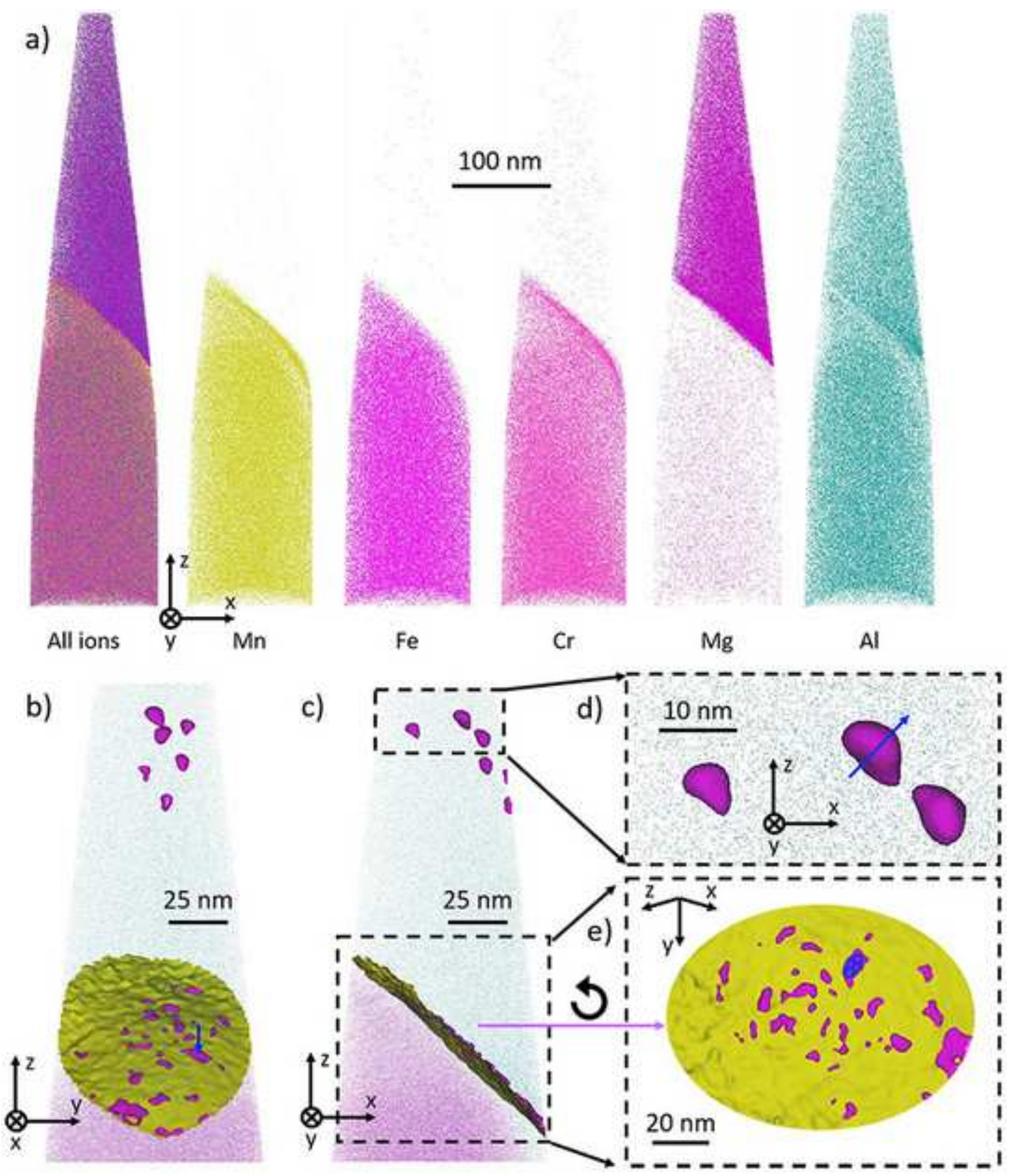



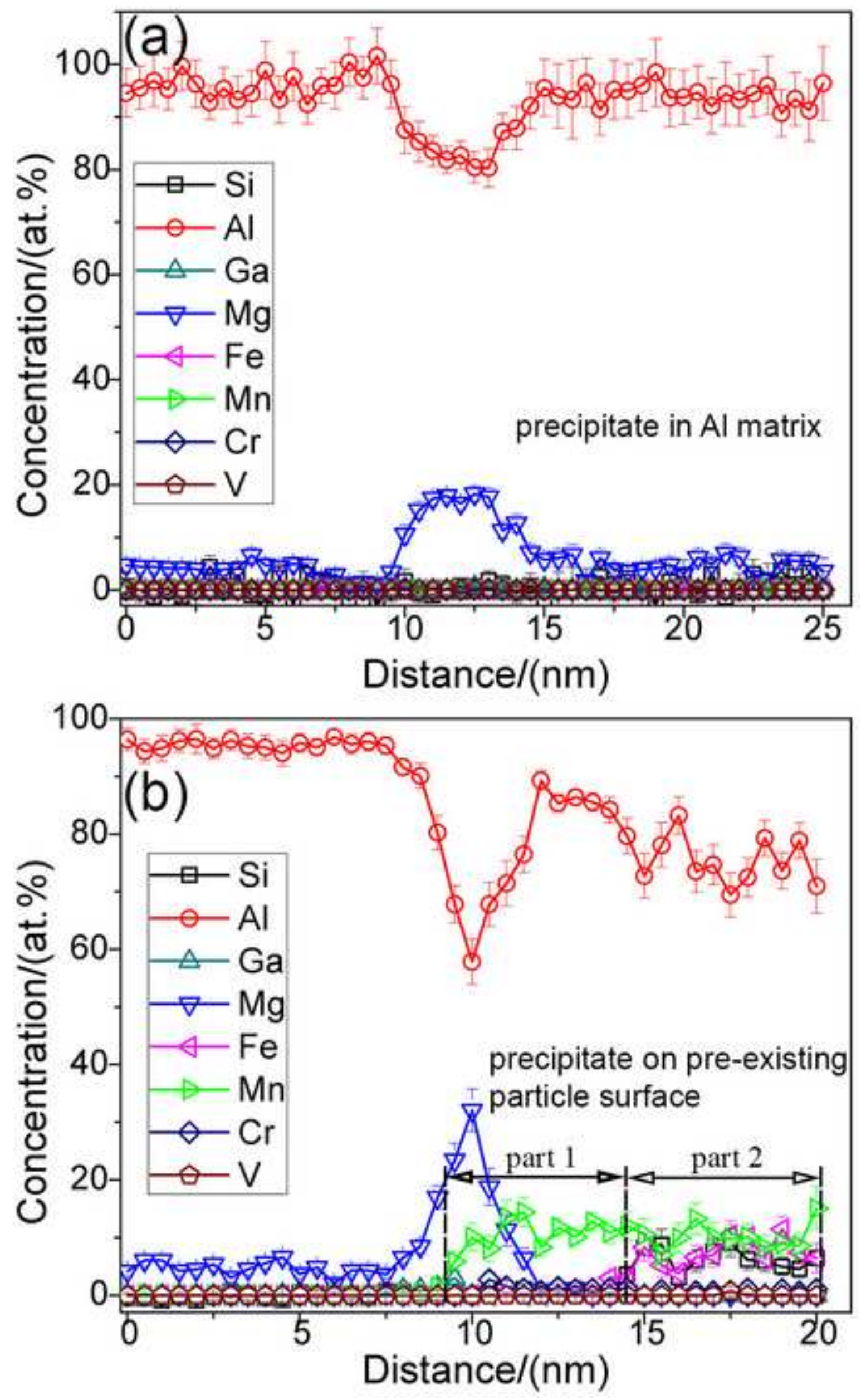


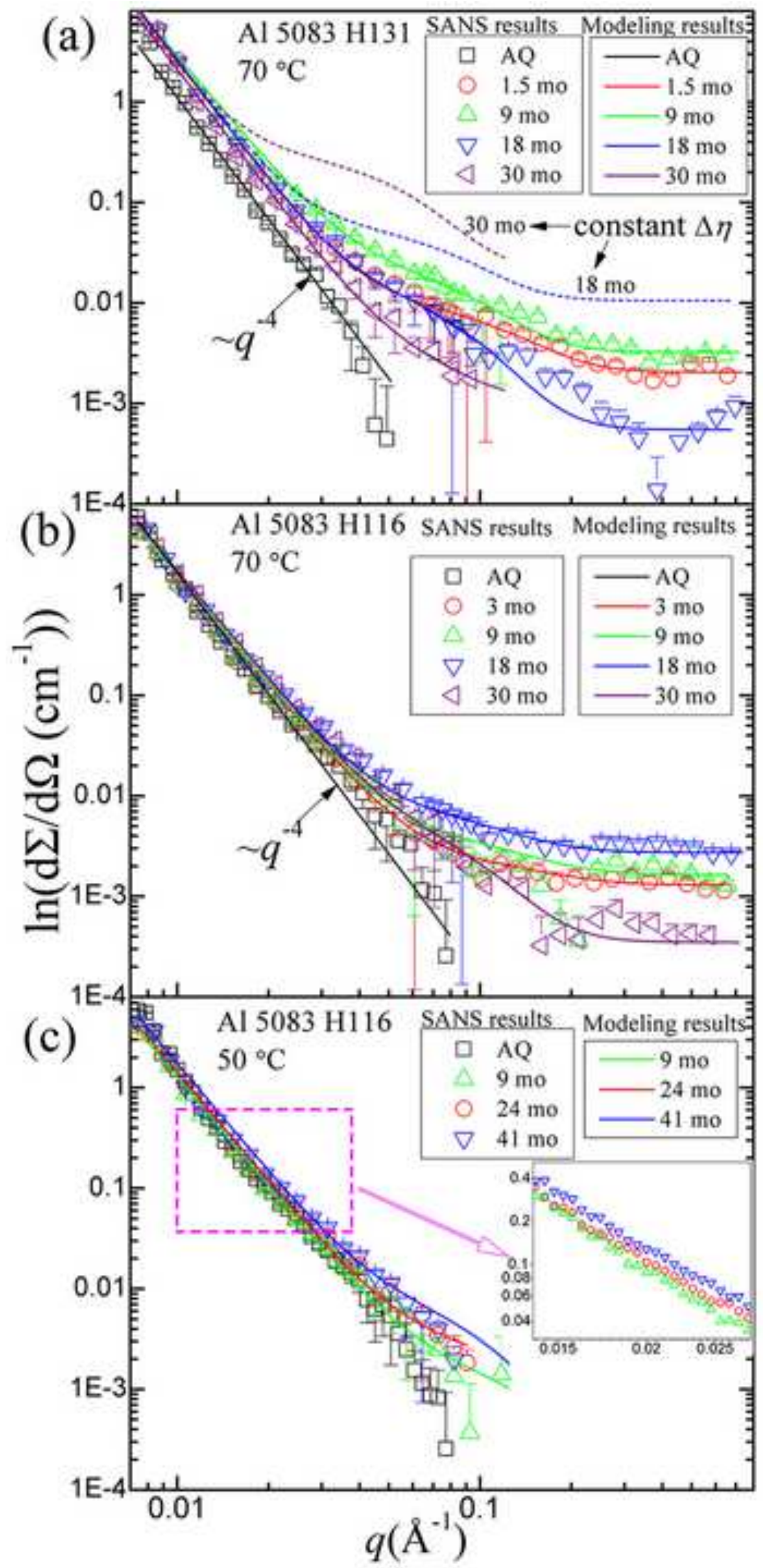




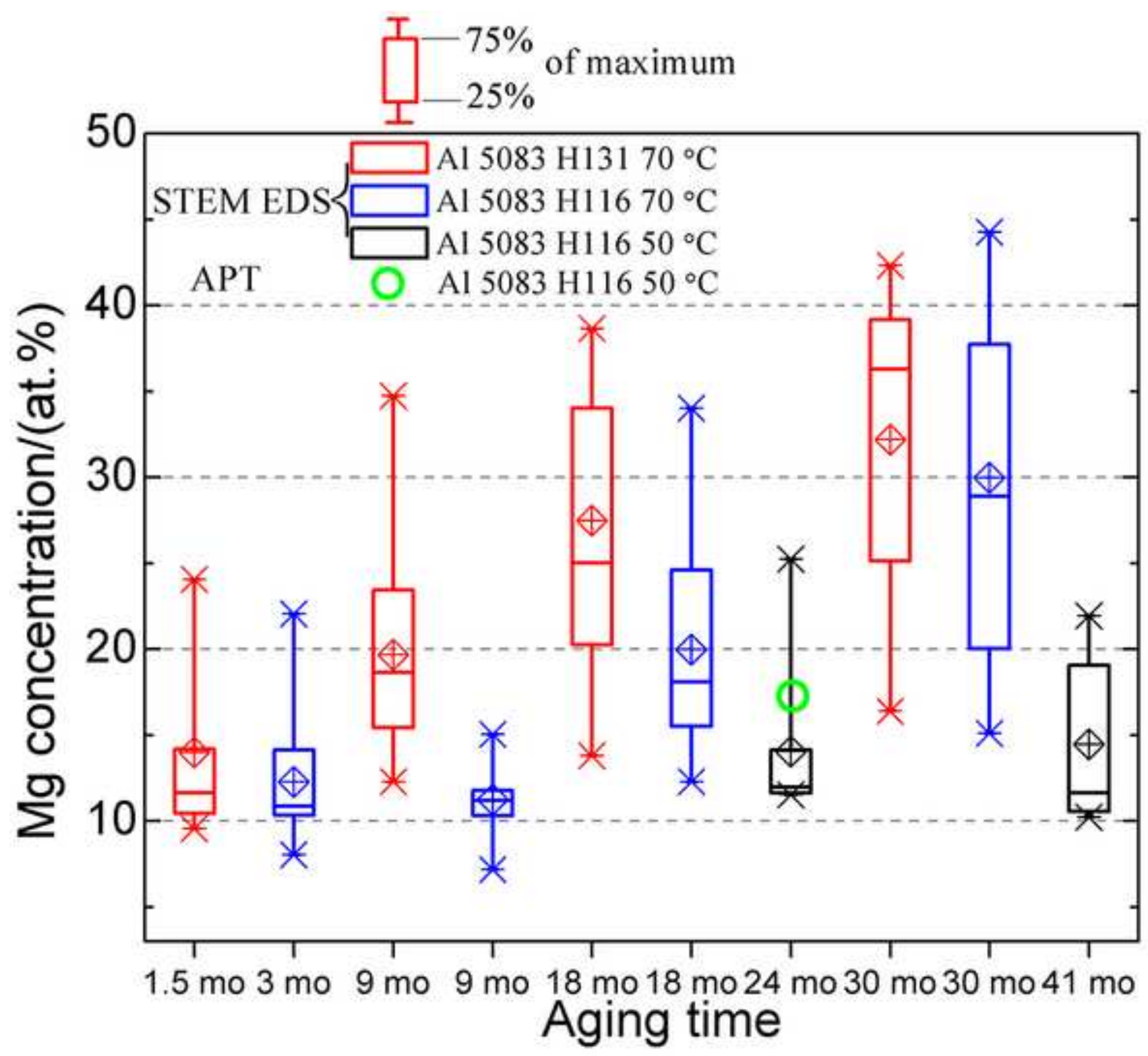



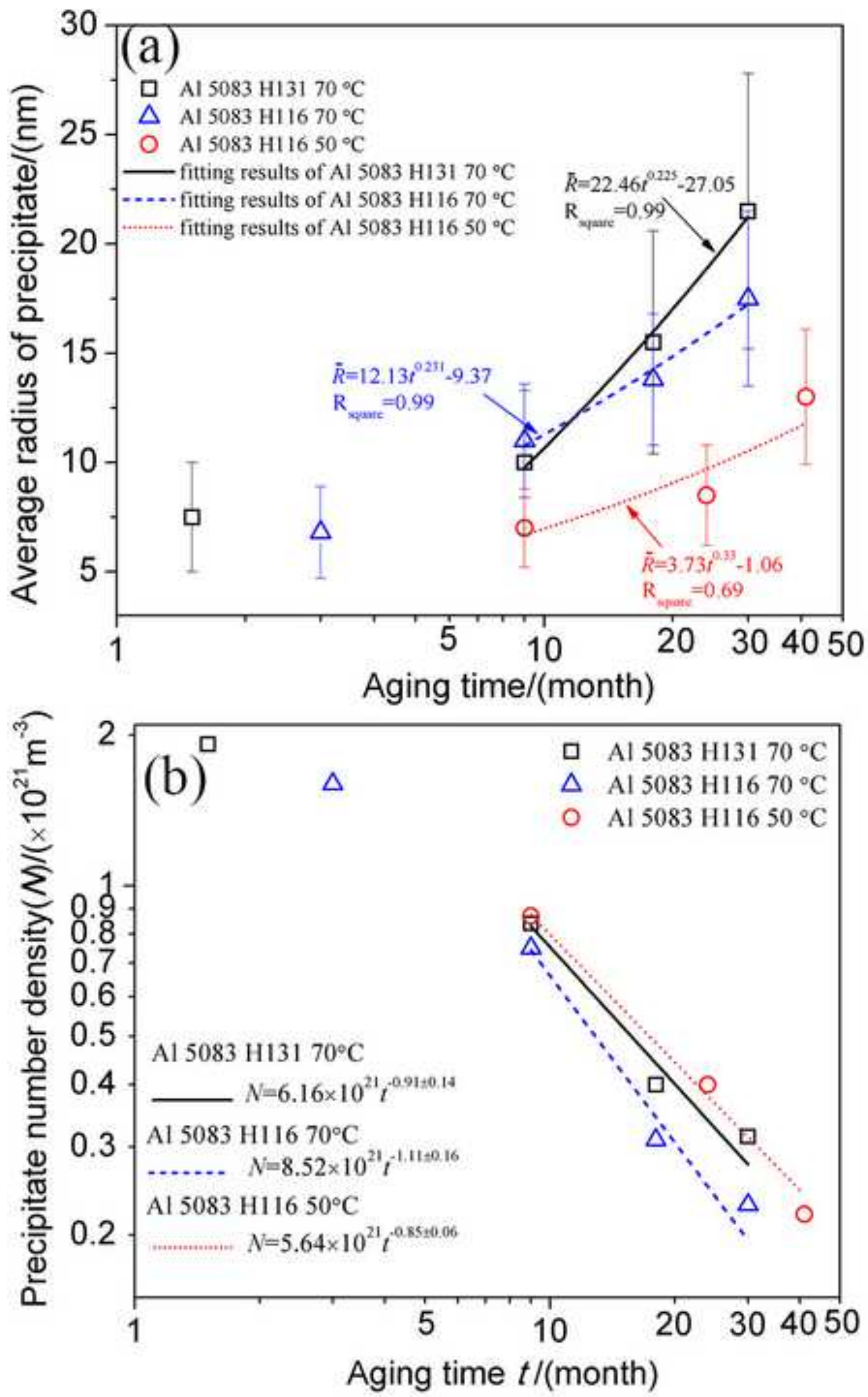


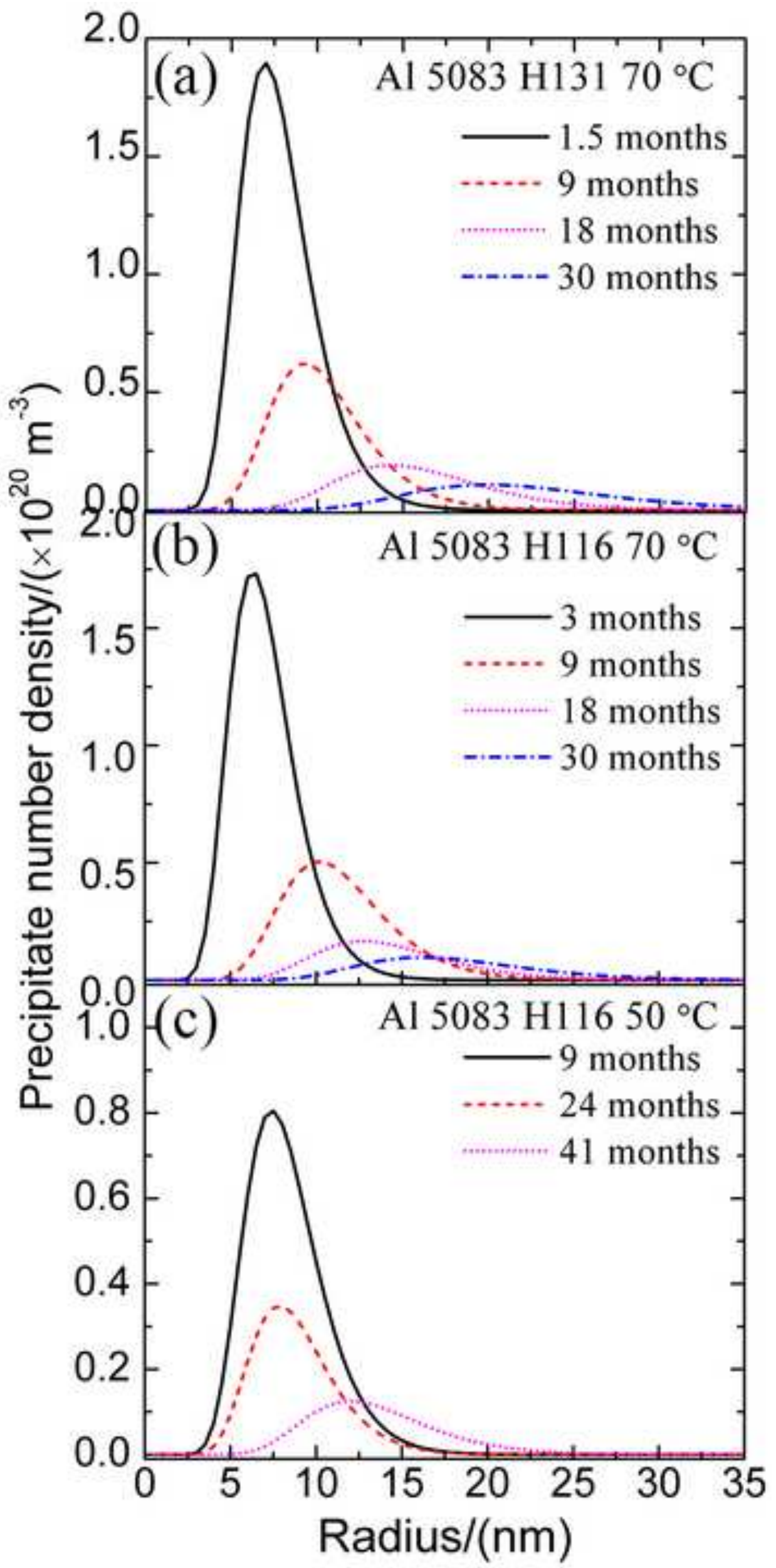

